\title{
HALL MOBILITY AND MAGNETORESISTANCE OF n-TYPE MAGNESIUM GERMANIDE
}

\author{
Ph.D. Thesis Submitted to lowa State University, \\ February, 1973
}

$$
\text { P. -W. Li }
$$

Ames Laboratory, USAEC lowa State University

Ames, lowa 50010

NOTICE

This report was prepared as an account of work sponsored by the United States Government. Neither the United States nor the United States Atomic Energy Commission, nor any of their employees, nor any of their contrators, subcontractors, or their employees, their contractors, subcontractor or implied, or assumes any makes any warranty, express or inplied, or assimes any legal liability or responsibility for the accuracy, completeness or usefulness of any information, apparatus, product or process disclused, ur represents that its use would not infringe privately owned rights.

Date of Manuscript: February, 1973 


\section{DISCLAIMER}

This report was prepared as an account of work sponsored by an agency of the United States Government. Neither the United States Government nor any agency Thereof, nor any of their employees, makes any warranty, express or implied, or assumes any legal liability or responsibility for the accuracy, completeness, or usefulness of any information, apparatus, product, or process disclosed, or represents that its use would not infringe privately owned rights. Reference herein to any specific commercial product, process, or service by trade name, trademark, manufacturer, or otherwise does not necessarily constitute or imply its endorsement, recommendation, or favoring by the United States Government or any agency thereof. The views and opinions of authors expressed herein do not necessarily state or reflect those of the United States Government or any agency thereof. 


\section{DISCLAIMER}

Portions of this document may be illegible in electronic image products. Images are produced from the best available original document. 
NOTICE

This report was prepared as an account of work sponsored by the United States Government. Neither the United States nor the United States Atomic Energy Commission, nor any of their employees, nor any of their contractors, subcontractors, or their employees, makes any warranty, express or implied, or assumes any legal liability or responsibility for the accuracy, completeness or usefulness of any information, apparatus, product or process disclosed, or represents that its use would not infringe privately owned rights.

Available from: National Technical Information Service Department $A$

Springfield, VA 22151

Price: Microfiche $\$ 0.95$ 
Hall mobllity and magnetoresistance of n-type magnesium germanide

by

Puo-wen LI

A Dissertation Submitted to the

Graduate Faculty in Partial Fulfillment of

The Requirements for the Degree of

DOCTOR OF PHILOSOPHY

Department: Physlcs

Major: Solid State Physics

\section{Approved:}

YCDanielear

In Chargo of Mojor Work

RG Barnes

For the Major Department

$\frac{\text { Chenlete Efodenack }}{\text { For the Groduate College }}$

lowa State University

Ames, lowa

1973 
TABLE OF CONTENTS

ABSTRACT

Page

ABSTRACT

I. INTRODUCTION

11. SAMPLE PREPARATION

111. EXPER IMENTAL METHOD

IV. ELECTRICAL RESISTIVITY

A. Intermediate Concentration Region . . . 8

B. High Concentration Region 13

V. HALL COEFFICIENT $\quad: \quad 14$.

VI. HALL MOBILITY. 18

A. Acoustic Mode Scattering 21

B. Ionized Impurity Scattering _ . 22

C. Neutral Impurity Scattering ... 26

D. Space Charge Scattering $\quad 27$

VII. MAGNETORESISTANCE 30

A. Theoretical Considerations $\quad 30$

B. Results and Analysis. 35

VIII. CONCLUSIONS $\quad \therefore \quad 50$

IX. LITERATURE CITED

X. ACKNOWLEDGMENTS

$X I$. APPENDIX $\quad 56$ 
Table 1. Values of activation energles $\epsilon_{1}$ and $\varepsilon_{3}$, cxhaus. tion Hall coefficient $\left(R_{H}\right)$ exh, exhaustion carrier concentration $n_{0}$, the estimated number of donors $N_{D}$, the mean interdonor distance $r_{s}$; the ratio $r_{s}$ to llie effective Bohr radius $a_{0}$; and the mobility ratio $b$ for seven $\mathrm{n}$-type $\mathrm{Mg}_{2} \mathrm{Ge}$ samples.

Table 2: Magnetoresistance coefficients in terms of the Hall mobility, anisotropy parameter, and relaxation time for $\langle 100\rangle$ type constant energy spheroids.

Table 3. Magnetoresistance coefficients $b, c$; and $d$, the dimensionless Seitz coefficients $b^{\prime}, c^{\prime}$, and $d^{\prime}$, the anisotropy parameter $K$, and the scattering factor $\langle\tau\rangle\left\langle\tau^{3}\right\rangle /\left\langle\tau^{2}\right\rangle^{2}$ of $n$-type $\mathrm{Mg}_{2} \mathrm{Ge}$.

Table 4. Analysis of $\mathrm{Mg}$, used in the preparation of $\mathrm{Mg}_{2} \mathrm{Ge}$, for impurities.

Table 5. Analysis of $\mathrm{Mg}_{2} \mathrm{Ge}$ samples for impurities. 
Fig. 1. Crystal orlentation for obtaining all three magnetoresistance coefficients from a single sample of $\mathrm{Mg}_{2} \mathrm{Ge}$. The current $\overrightarrow{\vec{T}}$ is in the [i12] direction and the magnetic field $\vec{H}$ is allowed to vary in the (îlo) plane.

Fig. 2. Temperature dependence of the resistivity of $\mathrm{Mg}_{2} \mathrm{Ge}$ from $4.2 \mathrm{~K}$ to $300 \mathrm{~K}$. The intrinsic line was obtained from Redin et al. The resistivities of samples 1-5 can be described by Eq. (1). The resistivities of the heavily doped samples 6 and 7 are almost Independent of temperature below $30 \mathrm{~K}$ as expected for a degenerate electron gas.

Fig. 3. Temperature dependence of the Hall coefficient of $\mathrm{Mg}_{2} \mathrm{Ge}$ from $4.2 \mathrm{~K}$ to $300 \mathrm{~K}$. The intrinsic line was obtained from Redin et al. The Hall coefficients of samples $1-5$ all have conspicuous maxima due to Impurlty band conduction. The Hall coefficients of the heavily doped samples 6 and 7 are almost independent of temperature and suggest overlapping of the conduction band and impurity band.

Fig. 4. Temperature dependence of the $\mathrm{Hall}$ mobillty of $\mathrm{Mg}_{2} \mathrm{Ge}$ from $4.2 \mathrm{~K}$ to $300 \mathrm{~K}$. Sample 2 showed marked inhomogeneity in resistivity at $77 \mathrm{~K}$, the other samples were quite homogeneous. For the homogeneous samples the Hall moblility from $150 \mathrm{~K}$ to $300 \mathrm{~K}$ had a $T-3 / 2$ temperature dependence, whlch indicates that intravalley acoustic mode scattering is dominant in this temperature range and that the symmetry of the conduction band minima. is $x_{3}$ rather than $x_{1}$.

Fig. 5. The anomalous temperature dependence of the Hall mobility of sample 2, which was found to be homogeneous in resistivity at $300 \mathrm{~K}$ but inhomogeneous at $77 \mathrm{~K}$. For temperatures greater than $300 \mathrm{~K}$ the moblitity is limited only by acoustlc mode scattering. For temperatures less than $200 \mathrm{~K}$ the mobility is limited by a combination of acoustic mode scattering and space charge scattering. The anomalous hump in the mobility curve between $200 \mathrm{~K}$ and $300 \mathrm{~K}$ occurs in the transition region. 
Fig. 6. The longltudinal and transverse magnetoresistance $\triangle p / p_{0}$ of seven samples of $\mathrm{Mg}_{2} \mathrm{Ge}$, which show the normal $H^{2}$ magnetic field dependence for $H$ up to 8 kOe. The symbol $L$ represents longitudinal $(\vec{T} \| \vec{H})$ and the symbol $T$ represents transverse $\left(\overrightarrow{{ }_{L}} \vec{H}\right)$ magnetoresistance.

Fig. 7. The magnetoresistance effect in $\mathrm{Mg}_{2} \mathrm{Ge}$ showing the angular dependence of $\triangle \rho / p_{0} H^{2}$ at $77 \mathrm{~K}$. For each sample $\Delta \rho / \rho_{0} H^{2}$ is described by Eq. (16), and a set of magnetoresistance coefficients $b, c$, and $d$ can be obtained from each curve. Since $b+c+d=0$ and $d<0$ we conclude that $n$-type $\mathrm{Mg}_{2} \mathrm{Ge}$ is a manyvalley semiconductor with constant energy spherolds in the $\langle 100\rangle$ directions.

Fig. 8. The magnetoresistance effect in $\mathrm{Mg}_{2} \mathrm{Ge}$ showing the angular dependence of $\triangle \rho / \rho_{0} \mathrm{H}^{2}$ for sample 4 at four stable temperatures. The symmetry condition for $\langle 100\rangle$ type spheroids is satisfled at all four temperatures. The values of the anisotropy parameter $K$ were found to decrease from 2.13 at $299.5 \mathrm{~K}$ to 1.65 at $43.6 \mathrm{~K}$.

Fig. 9. The magnetoresistance effect of $\mathrm{Mg}_{2} \mathrm{Ge}$ showing the angular dependence of $\Delta \mathrm{O} / \mathrm{p}_{0} \mathrm{H}^{2}$ at $77 \mathrm{~K}$ for three inhomogeneous samples. Values of $\Delta \rho / \mathrm{poH}^{2}$ are about an order of magnitude higher than the values for homogeneous samples shown in Fig. 7. $\Delta p / \mathrm{po}_{\mathrm{O}}{ }^{2}$ was insensitive to the angle $\theta$ between $\vec{P}$ and $\vec{H}$ in sharp contrast to the effects observed with homogeneous samples (Figs. 7 and 8 ).

Fig. 10. Block diagram of the apparatus. 


\section{ABSTRACT}

The electrical resistivity, Hall coefficient, and weak-field magnetoresistance of homogeneous single crystals of $\mathrm{n}$-type $\mathrm{Mg}_{2} \mathrm{Ge}$ have been measured. The samples were elther Al-doped or undoped, and had exhaustion carrier concentrations from $1.3 \times 10^{16} \mathrm{~cm}^{-3}$ to $8.2 \times 10^{17} \mathrm{~cm}^{-3}$. The electrical resistivity and Hall coefficlent were measured from $4.2 \mathrm{~K}$ to $300 \mathrm{~K}$. Impurity band conduction was observed at the lower temperatures. The Hall mobility from $150 \mathrm{~K}$ to $300 \mathrm{~K}$ had a $T^{-3 / 2}$ temperature dependence which indicates that intravalley acoustic mode scattering is the dominant scattering mechanism in this temperature range. From a consideration of the selection rules and this Hall mobility temperature dependence, we conclude that the symmetry of the conduction band minima is $x_{3}$ rather than $x_{1}$. The weak-field magnetoresistance of $\mathrm{Mg}_{2} \mathrm{Ge}$, which was measured at $77.4 \mathrm{~K}$ and at three other stable temperatures $(43.6 \mathrm{~K} ; 194.5 \mathrm{~K}$ and $299.5 \mathrm{~K})$, was found to be much smaller than the magnetoresistance of $\mathrm{Ge}$ and $\mathrm{Mg}_{2} \mathrm{Sn}$. The magnetoresistance coefficients $b, c$, and $d$ were obtained from these measurements and found to satisfy the symmetry relations $b+c+d=0, d<0$. This result confirms the theoretical prediction that $n$-type $\mathrm{Mg}_{2} \mathrm{Ge}$ is a manyvalley semiconductor with constant energy spheraids in the $\langle 100\rangle$ directions. The anisotropy parameter $K$ was between 1.51 and 1.78 at $77 \mathrm{~K}$. Inhomogeneous samples showed anomalies in the Hall mobilities and in the magnetores/stances. 


\section{INTRODUCTION}

Magnesium germanide is a semiconductor of the $\mathrm{Mg}_{2} \mathrm{X}$ family (where $X$ can be $\mathrm{Si}, \mathrm{Ge}, \mathrm{Sn}$, or $\mathrm{Pb}$ ) which crystallizes in the antifluorite structure. The space group for $\mathrm{Mg}_{2} \mathrm{Ge}$ is $\mathrm{Fm} 3 \mathrm{~m}$. A fairly complete study of the $\mathrm{Hall}$ mobility of $\mathrm{Mg}_{2} \mathrm{Ge}$ above $77 \mathrm{~K}$ has been made by Redin et al. However, no work has been reported on the Hall mobility of $\mathrm{Mg}_{2} \mathrm{Ge}$ below $77 \mathrm{~K}$. The first objective of this work was to study the electrical properties of n-type $\mathrm{Mg}_{2} \mathrm{Ge}$ from $4.2 \mathrm{~K}$ to $77 \mathrm{~K}$.

The electronic structure of the $\mathrm{Mg}_{2} \mathrm{X}$ compounds has been investigated theoretically by Lee, ${ }^{2}$ Folland, ${ }^{3}$ Foll and and Bassani, 4 Au-Yang and Cohen, 5 and Van Dyke and Herman. ${ }^{6}$ Three of these theoretical papers $2,4,5$ predict that $\mathrm{Mg}_{2} \mathrm{Ge}$ has its valence band maximum at the center of the Brillouin zone $\Gamma$, with symmetry $\Gamma_{15}$, and has $i$ ts conduction band minima at the points $X$ which are in the $\langle 100\rangle$ directions. Experimentally, the piezoresistance measurements on $n$-type $\mathrm{Mg}_{2} \mathrm{Si}$ by Whitten and Danielson ${ }^{7}$ and on $n$-type $\mathrm{Mg}_{2} \mathrm{Sn}$ by Crossman and Danielson, 8 and the magnetoresistance study of $\mathrm{Mg}_{2} \mathrm{Sn}$ by Umeda ${ }^{9}$ have shown the conduction band of these two semiconductors to be many-valleyed with minima in the $\langle 100\rangle$ directions. Magnetoresistance measurements of $\mathrm{Mg}_{2} \mathrm{~Pb}$ by Stringer and Higgins ${ }^{10}$ have shown that this compound also obeys the symmetry conditions for $\langle 100\rangle$ type spheroids. Stella et al. ${ }^{11}$ have reported the pressure coefficients of the band gaps of $\mathrm{Mg}_{2} \mathrm{Si}$ and $\mathrm{Mg}_{2} \mathrm{Ge}$ to be nearly the same which suggests that the symmetries of the band gaps for these two compounds may be similar. Infrared absorption experiments by Lott and Lynch ${ }^{12}$ indicate that the band 
gap of $\mathrm{Mg}_{2} \mathrm{Ge}$ is indirect and has a valence band maximum at $\Gamma$. However, no direct experimental work has been reported on the orientation of the conduction band minima of $\mathrm{Mg}_{2} \mathrm{Ge}$. The band calculation by Lee ${ }^{2}$ suggested that the conduction band minima of $\mathrm{Mg}_{2}$ Ge have $x_{1}$ symmetry, but more recent work by Au-Yang and Cohen ${ }^{5}$ showed that the conduction band minima have $x_{3}$ symmetry. Folland and Bassani ${ }^{4}$ examined the selection rules of $\mathrm{Mg}_{2} \mathrm{Ge}$ and indicated that the Hall mobillty temperature dependence near room temperature can be used to identify this symmetry. The second objective of this research was to determine the orientation of the conduction band minima of $\mathrm{Mg}_{2} \mathrm{Ge}$ experimentally by the measurement of magnetoresistance, and to determine the symmetry of the conduction band minima from the Hall mobility temperature dependence near room temperature. 


\section{SAMPLE PREPARATION}

Single crystals of $\mathrm{Mg}_{2} \mathrm{Ge}$ were prepared by a modified Bridgman method in which the molten compound with a temperature gradient of $25 \mathrm{~K}$ per $\mathrm{cm}$ was cooled through the freezing point $(1388 \mathrm{~K})$. Single crystals $2 \mathrm{~cm}$ in diameter and $6 \mathrm{~cm}$ long were frequently obtained.

In order to produce a pure compound semiconductor it is desirable to have pure constituents. High purlty germanium was available from commercial sources, but commercially available magnesium was rather impure. The stated purity of Dow Chemical Company magnesium was 99.95 percent. It was therefore necessary to develop a method for purification of the magnesium. The method developed by Grotzky and sidles ${ }^{13}$ was found to be successful. The magnesium was placed in a vacuum furnace and purified by sublimation at a pressure of

$10^{-9}$ Torr. The starting magnesium had a resistivity ratio $\rho_{300 \mathrm{~K}} / \mathrm{P}_{4.2} \mathrm{~K}$ of 200 to 400; the purified material had a resistivity ratio of about 2000. Mass spectrographic analys is at the Ames Laboratory showed a substantial reduction in the total amount of impurities. 14 The mass spectrographic analysis of Mg for impurities is shown in the Appendix (Table 4).

Instead of the more conventional [110] oriented crystal ${ }^{15}$ in order to obtain all three magnetoresistance coefficients b, $c$, and d from a single sample, we used the orientation shown in Fig. 1. The current $\vec{T}$ is along the direction [iT2] which lies in the cleavage plane. The direction of the magnetic field is allowed to vary in the (i10) plane which contains the directions [111] and [īi2]. It is easy 
THIS PAGE

\section{WAS INTENTIONALLY \\ LEFT BLANK}


Fig. 1. Crystal orientation for obtaining all three magnetoresistance coefficients from a single sample of $\mathrm{Mg}_{2} \mathrm{Ge}$. The current $\mathrm{T}^{*}$ is in the [īi2] direction and the magnetic field $\vec{H}$ is altowed to vary in the $(\bar{i} 10)$ plane. 


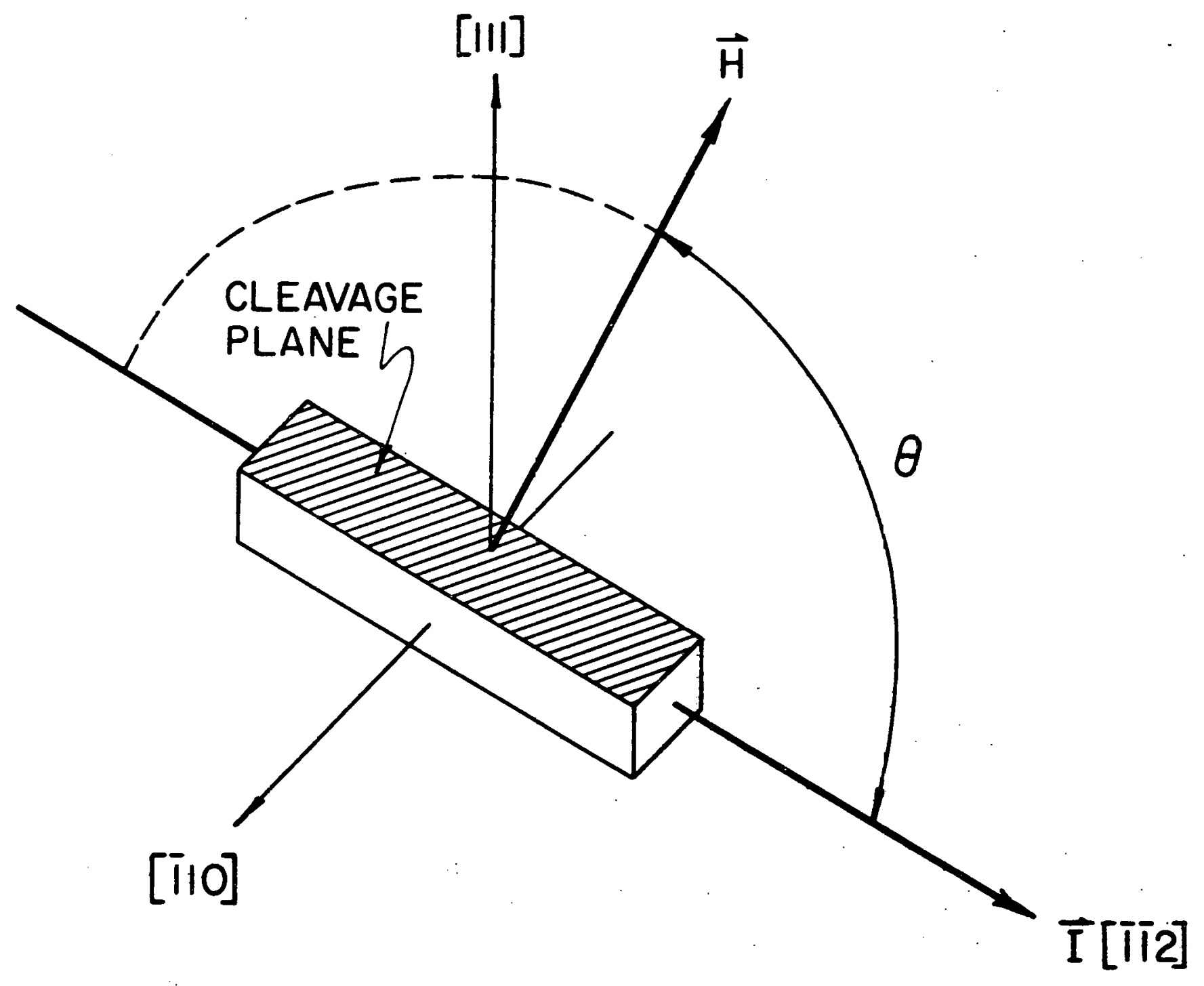


to prepare such samples with accurate orientations, since $\mathrm{Mg}_{2} \mathrm{Ge}$ single crystals cleave along the (111) plane very easily. The resistivity and Hall coefficient were also measured as functions of temperature for the same sample.

Samples were roughly oriented from observation of the (111) cleavage planes, and accurately oriented within two degrees of the required orientation by $x$-ray diffraction. The oriented samples were cut from the ingot by a wire saw, lapped by hand, and cleaned by an air abrasive. Dimensions of the samples were $1.4 \times 1.4 \times 12 \mathrm{~mm}^{3}$. Samples exposed to air for 24 hours showed little deterioration. In the presence of water vapor $\mathrm{Mg}_{2} \mathrm{Ge}$ will deteriorate, probably forming $\mathrm{GeH}_{4}$ and $\mathrm{MgO}$. The samples were tested for electrical homogeneity by moving resistivity probes along the sample first at room temperature and then at liquid nitrogen temperature. Both homogeneous and. inhomogeneous samples were used in this experiment in order to identify spurious effects. 


\section{II. EXPERIMENTAL METHOD}

A description of the apparatus used for this experiment has been given by Lee. ${ }^{16}$ Briefly, all resistivities and Hall coefficients were measured by a Rubicon potentiometer with a Keithley 148 nanovoltmeter as a null detector. A Keithiey 640 vibrating capacitor electrometer was required when the resistance of the sample was very high. For magnetoresistance measurements a highly stable constant current of 1 to $30 \mathrm{~mA}$ was obtained from a constant current supply designed by Kroeger and Rhinehart ${ }^{17}$ at the Ames Laboratory. The change in voltage due to the magnetic field was read within $50 \mathrm{nV}$ from a Rubicon model 2772 potentiometer. The magnetoresistance data were measured at $15^{\circ}$ intervals from zero to $180^{\circ}$. Four readings were taken at each angle corresponding to both directions of the magnetic field and of the current. Spurlous voltages, such as those arising from Hall and thermal effects, were thereby minimized.

A block diagram of the experimental arrangement is shown in the Appendix (Fig, 10). 


\section{ELECTRICAL RESISTIVITY}

The resistivities versus reciprocal temperature of seven $n$-type $\mathrm{Mg}_{2} \mathrm{Ge}$ samples from $4.2 \mathrm{~K}$ to $300 \mathrm{~K}$ are shown in Fig. 2. Only sample 2 shows intrinsic behaviour within our temperature range. The intrinsic line for sample 2 agreed well with the extension of the intrinsic line obtained by Redin et al.

\section{A. Intermediate Concentration Region}

The temperature dependence of the resistivity $\rho_{0}$ for samples $1-5$ may be represented by the sum of three exponentials as suggested by Fritzsche 18

$$
1 / p_{0}=c_{1} \exp \left(-\epsilon_{1} / k T\right)+c_{2} \exp \left(-\varepsilon_{2} / k T\right)+c_{3} \exp \left(-\varepsilon_{3} / k T\right),
$$

where $\varepsilon_{1}, \varepsilon_{2}$, and $\varepsilon_{3}$ represent activation energies. The quantity $\varepsilon_{1}$ is the activation energy for exciting an electron into the conduction band, and $\epsilon_{3}$ is the activation energy for impurity conduction. In the theoretical model impurity conduction occurs by electrons hopping from occupled to unoccupied donor states with the aid of phonons. 19,20 The quantity $\varepsilon_{2}$ is the activation energy for thermal excltation of electrons from the donor ground state to an impurity band formed by the interaction of ionized donors. 21,22 The resulting $\varepsilon_{1}$ and $\varepsilon_{3}$ values of these five samples are shown in Table 1. The temperature region represented by $\epsilon_{2}$ for these samples does not have a distinct linear range as reported by Fritzsche ${ }^{18}$ for germanium. Rather this 
THIS PAGE

\section{WAS INTENTIONALLY \\ LEFT BLANK}


Fig. 2. Temperature dependence of the resistivity of $\mathrm{Mg}_{2} \mathrm{Ge}$ from 4.2 $\mathrm{K}$ to $300 \mathrm{~K}$. The intrinsic: line was obtained from Redin et al. The resistivities of samples $1-5$ can be described by Eq. (1). The resistivities of the heavily doped samples 6 and 7 are almost independent of temperature below $30 \mathrm{~K}$ as expected for a degenerate electron gas. 


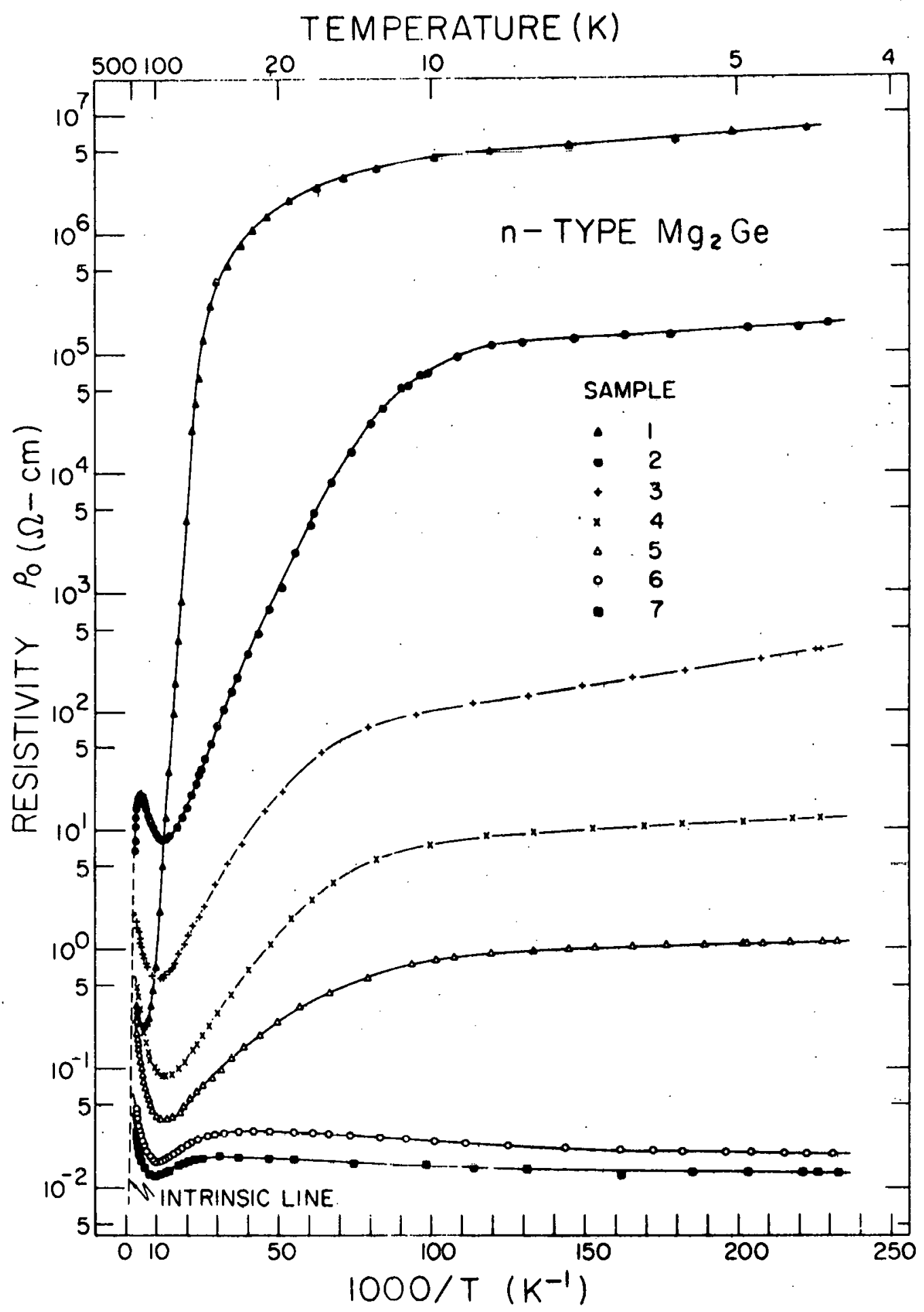


Table 1. Values of activation energies $\varepsilon_{1}$ and $\varepsilon_{3}$, exhaustion Hall coefficient ( $\left.R_{H}\right)$ exh, exhaustion carrier concentration $n_{0}$, the estimated number of donors $N_{D}$, the mean interdonor distance $r_{s}$, the ratio of $r_{s}$ to the effective Bohr radius $a_{0}$, and the mobility ratio $b$ for seven n-type $\mathrm{Mg}_{2} \mathrm{Ge}$ samples.

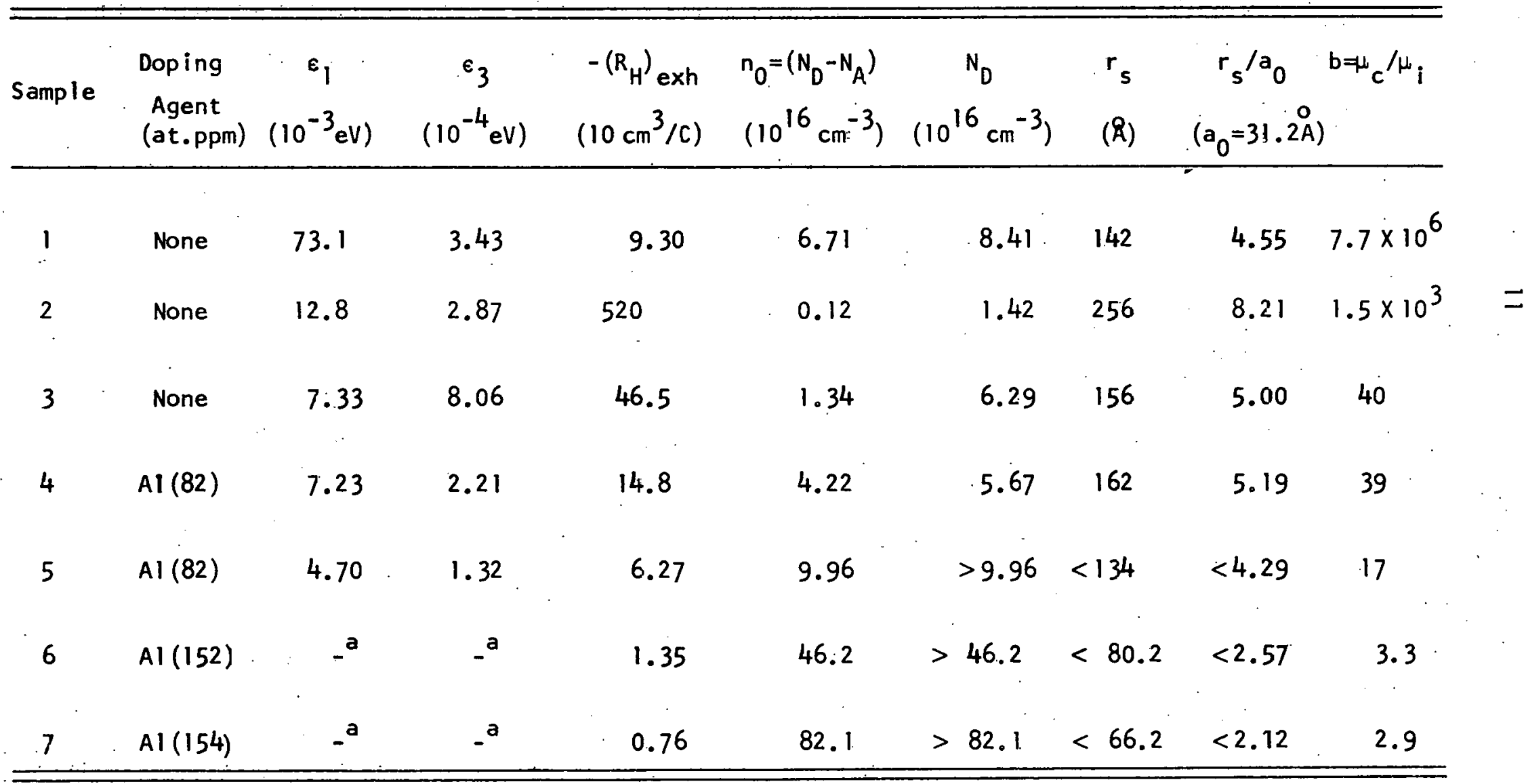

Metalilic conduction. 
region is characterized by a gradual change in slope between the temperature regions represented by $\varepsilon_{1}$ and $\varepsilon_{3}$.

In order to compare the thermal ionization energy $E_{D}$ with the experimental $\epsilon_{1}$ values, we assume a hydrogenic nature for the donor impurities and estimate the thermal ionization energy from the expres$\operatorname{sion}^{23} E_{D}(e V)=\left(13.6 / \varepsilon_{0}^{2}\right)\left(m^{*} / m_{0}\right)$, where $m_{0}$ is the free electron mass. According to McWilliams and Lynch, ${ }^{24}$ the static dielectric constant $\epsilon_{0}$ of $\mathrm{Mg}_{2} \mathrm{Si}$ is 20 , and we assume the static dielectric constant of $\mathrm{Mg}_{2} \mathrm{Ge}$ is also about 20. The electron effective mass $\mathrm{m}^{*}$ of $\mathrm{Mg}_{2} \mathrm{Ge}$ according to Redin et al.' was estimated to be about $0.18 \mathrm{~m}_{0}$. These two values give $E_{D}=6.12 \times 10^{-3} \mathrm{eV}$ which is only half the value $\varepsilon_{1}=1.28 \times 10^{-2} \mathrm{eV}$. of sample 2 .

Lee ${ }^{2}$ obtained theoretical electron effective masses of $m_{l}^{*}=0.63 \mathrm{~m}_{0}$ and $m_{t}^{*}=0.25 m_{0}$. If we assume $m^{*}$ is approximately the geometric mean mass, 23 obtained from the expression $m^{*}=\left(m_{l}^{*} m_{t}^{* 2}\right)^{1 / 3}$, then $m^{*} \approx 0.34 m_{0}$. The $\mathrm{m}^{*}$ value gives $E_{D}=1.16 \times 10^{-2}$ which is in good agreement with the experimental $\varepsilon_{1}$ value of sample 2. We believe, therefore, that the mean effective mass for the electrons in $\mathrm{Mg}_{2} \mathrm{Ge}$ is closer to $0.34 \mathrm{~m}_{0}$ calculated by Lee ${ }^{2}$ than to 0.18 "lo estimated by Redin et al.'

The decrease in $\varepsilon_{1}$ for sample 3, 4, and 5, when compared to sample 2, is due to the increased broadening of the impurity band. 25 The value of $\varepsilon_{1}$ for sample 1 is seven times greater than the estimated value of $E_{D}$. Therefore, this deep lying donor level can not be understood on the basis of the simple hydrogen model. This large value of $e_{1}$ was also obtalned for two additional samples. Its nature is unknown. 


\section{B. High Concentration Region}

The almost temperature independent resistivities of sample 6 and 7 below $30 \mathrm{~K}$ is characteristic of a degenerate electron gas. The transition to metallic conduction has been predicted by Mott and Twose $^{20}$ to occur when the ratio of the mean interdonor distance $r_{s}$ to the effective Bohr radius $a_{0}$ is about 3 ; that is,

$$
r_{s} / a_{0} \approx 3
$$

Here $r_{5}=\left(3 / 4 \pi N_{D}\right)^{1 / 3}$, where $N_{D}$ is the donor concentration; and $a_{0}=\epsilon_{0}\left(m_{0} / m^{*}\right) a_{H}$ where $a_{H}(0.53 \AA)$ is the Bohr radius of a hydrogen atom.

Table 1 shows the mean interdonor distance $r_{s}$ for each sample. If we take Lee's mean effective mass $m^{* *}=0.34 m_{0}$ and $\epsilon_{0}=20$, we obtain an effective Bohr radius $a_{0}=31.2 \AA$. Equation (2) is then satisfied for the highly doped samples 6 and 7 only. This result is consistent with the flat resistivity curves of samples 6 and 7 shown in Fig. 2 . 


\section{HALL COEFFICIENT}

The Hall coefficients $R_{H}$ versus reciprocal temperature are shown in Fig. 3 for samples $1-7$ in the temperature range $4.2 \mathrm{~K}$ to $300 \mathrm{~K}$. Hall coefficients were measured nearly down to $4.2 \mathrm{~K}$ for samples 4-7. However, the Hall voltage was difficult to measure below $10 \mathrm{~K}$ for samples 2 and 3 and below $27 \mathrm{~K}$ for sample 1 because of contact noise and small Hall signals. The Hall coefficient in the intrinsic range of sample 2 agrees with the intrinsic line by Redin et al.' The Hall coefficients of all samples remained negative throughout the entire temperature range indicating donor impurities in the extrinsic range, and electron mobilities greater than hole mobilities in the intrinsic range. $R_{H}$ was independent of magnetic field strength at least up to $8 \mathrm{koe}$. The formula $R_{H}=-1 /\left(N_{D}-N_{A}\right)$ e was used to obtain the exhaustion carrier concentration $n_{0}=\left(N_{D}-N_{A}\right)$ shown in Table 1. For simplicity we neglect the factor $3 \pi / 8$ and assume the Hall mobility and drift mobility to be equal.

The Hall coefficient curves in Fig. 3 of samples 1-7 all have conspicuous maxima. Hung and Gliessman, ${ }^{26}$ and Conwel1 $1^{27}$ interpreted the Hall coefficlent for a sample with an intermediate or high concentration of donor impurities in terms of a two-band model - a conduction bend and an Impurlty band. We have used this two-band model to analyze the Hall data for samples 1-7. The carrier concentration and mobility are represented by $n_{c}$ and $\mu_{c}$ in the conduction band and by $n_{i}$ and $\mu_{i}$ in the impurity band. Introducing the mobility ratio $b=\mu_{c} / \mu_{i}$ and assuming this ratio is temperature independent, Conwel1 27 gives an 
THIS PAGE

\section{WAS INTENTIONALLY LEFT BLANK}


Fig. 3. Temperature dependence of the Hall coefficient of $\mathrm{Mg}_{2} \mathrm{Ge}$ from $4.2 \mathrm{~K}$ to $300 \mathrm{~K}$. The intrinsic I ine was obtained from Redin et al. The Hall coefficients of samples 1-5 all have conspicuous maxima due to impurity band conduction. The Hall coefficients of the heavily doped samples 6 and 7 are almost independent of temperature and suggest overlapping of the conduction band and impurity band. 


\section{6}

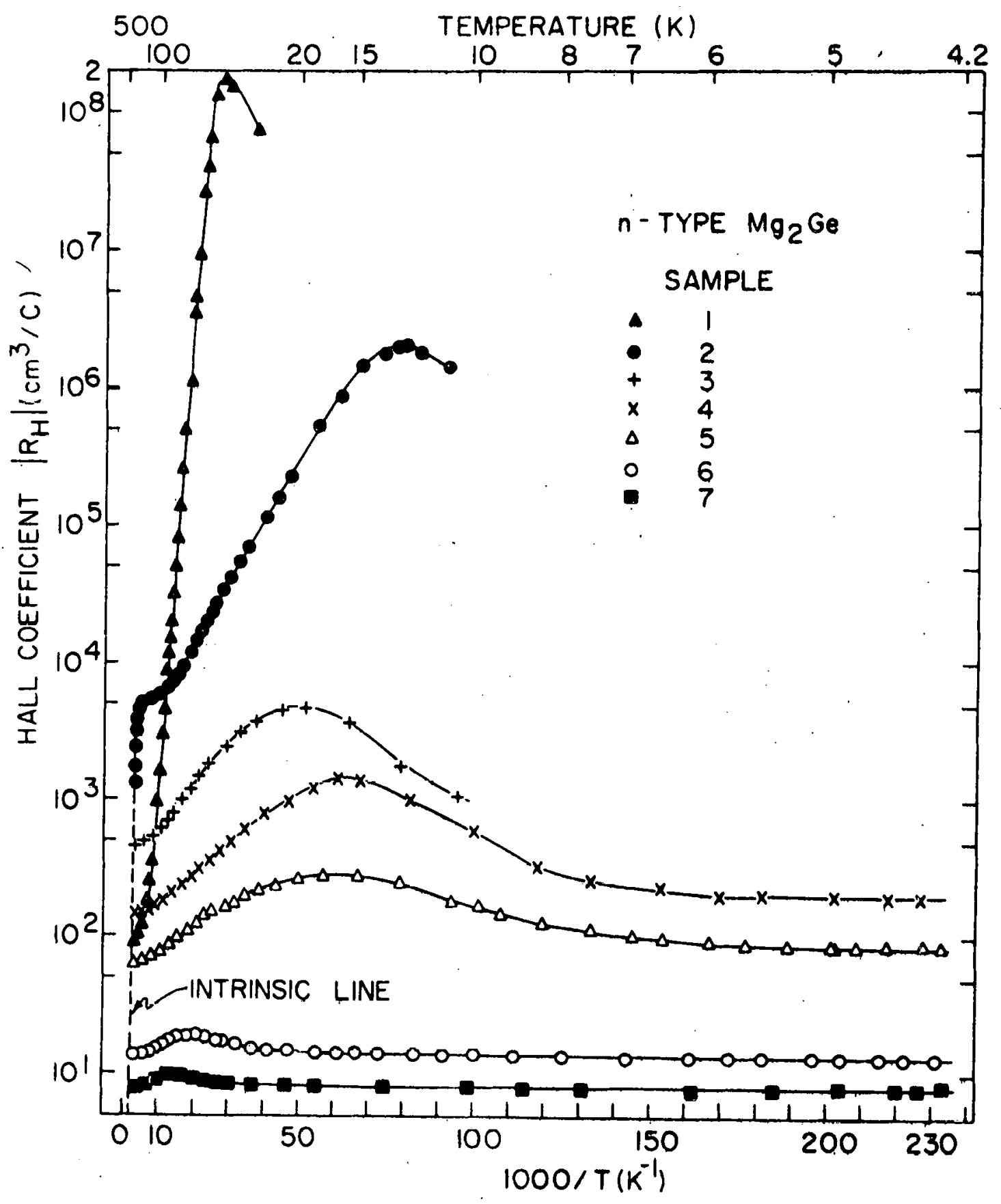


expression for $b$ in terms of the exhaustion Hall coefficient $\left(R_{H}\right)$ exh and the maximum Hall coefficient $\left(R_{H}\right)_{\max }$

$$
\left(R_{H}\right)_{\text {exh }} /\left(R_{H}\right)_{\max }=4 b /(b+1)^{2} .
$$

The values of $\left(R_{H}\right)_{\max }$ may be obtained from Fig. 3 , and the values of $\left(R_{H}\right)$ exh are given in Table 1. The b values calculated from Eq. (3) for samples 1-7 are also shown in Table. 1 . 
VI. HALL MOBILITY

The Hall mobilities $\mu_{H}=R_{H} / p_{0}$ for samples $1-7$ are shown as functions of temperature in Fig. 4. Samples 6 and 7, which have the highest impurity content, have electron mobilities which are nearly temperature independent below $40 \mathrm{~K}$. Such behavior is characteristic of a degenerate electron gas. At temperatures below $10 \mathrm{~K}$ the mobilities of the electrons for samples 6 and 7 are much greater than for the other samples. Similar crossing of the mobility curves has been reported by Conwe $11^{27}$ on Ge and on GaP by Casey et al. ${ }^{28}$

At very low temperatures, samples $1-5$ have electron mobilities which decrease sharply with decreasing temperature owing to the onset of impurity band conduction. The expression for mobility in the twoband model, according to Khosla, 29 is

$$
\mu_{H}=\left(\mu_{c} / b\right)\left(n_{c} b^{2}+n_{i}\right) /\left(n_{c} b+n_{i}\right)
$$

If $n_{c} \gg n_{i}, \mu_{H}=\mu_{c}$ and the mobility is the mobility of electrons in the conduction band. If $n_{c} \ll n_{i}, \mu_{H}=\mu_{i}$ and the mobility is the mobllity of electrons in the impurily band. For the intermediate case Khosla ${ }^{29}$ considers a large number of charge carriers to be in the Impurity band, but a substantial fraction to be still in the conduction band. In this case $n_{c} b^{2}>n_{i}>n_{c} b$. The mobility is then

$$
\mu_{H}=\mu_{c} b\left(n_{c} / n_{i}\right)
$$

From Eq. (5), the rapid decrease (greater than $T^{3 / 2}$ ) of the mobility 
THIS PAGE

\section{WAS INTENTIONALLY LEFT BLANK}


Fig. 4. Temperature dependence of the Hall mobility of $\mathrm{Mg}_{2} \mathrm{Ge}$ from $4.2 \mathrm{~K}$ to $300 \mathrm{~K}$. Sample 2 showed marked inhomogeneity in resistivity at $77 \mathrm{~K}$, the other samples were quite homogeneous. For the homogeneous samples the Hall mobility from $150 \mathrm{~K}$ to $300 \mathrm{~K}$ had a $\mathrm{T}^{-3 / 2}$ temperature dependence, which indicates that intravalley acoustic mode scattering is dominant in this temperature range and that the symmetry of the conduction band minima is $x_{3}$ rather than $x_{1}$. 


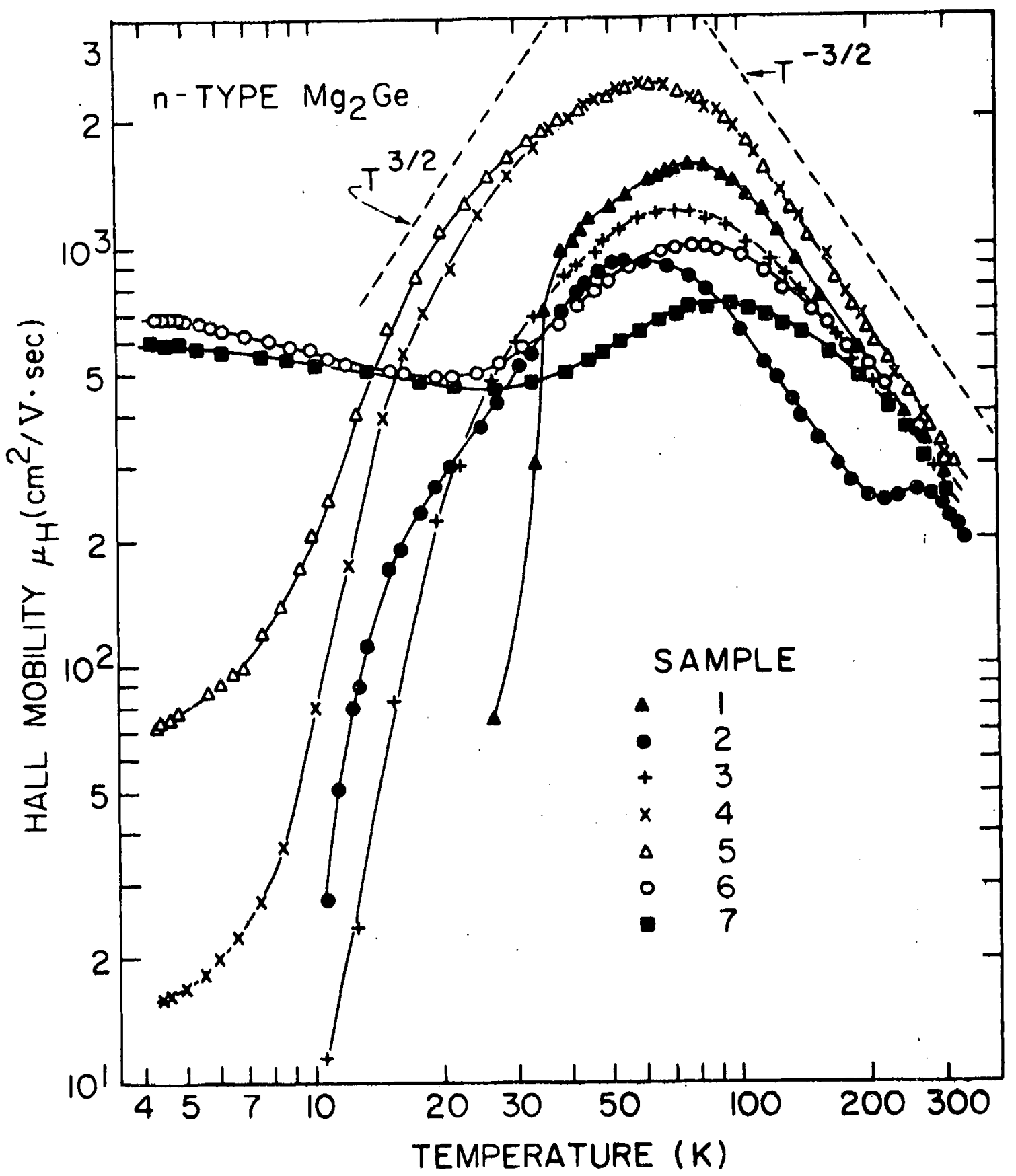


of sample 1 below $40 \mathrm{~K}$, sample 3 below $30 \mathrm{~K}$, and samples 2, 4, 5 below $20 \mathrm{~K}$ is attributed to the corresponding decrease of the ratio $n_{c} / n_{i}$ in each sample. For samples 4 and 5 below $7 \mathrm{~K}$, the mobilities tend to saturate. Below this temperature the majority of the electrons are in the impurity band and $\mu_{H}$ approaches the constant $\mu_{i}$ values.

\section{A. Acoustic Mode Scattering}

Some information regarding band structure and intervalley scattering can be deduced from the dependence of the Hall mobility on temperature (Fig. 4). From $150 \mathrm{~K}$ to $300 \mathrm{~K}$ the Hall mobilities show very nearly a $T^{-3 / 2}$ dependence upon temperature for all homogeneous samples (that is, all samples except sample 2). In this temperature range acoustic mode scattering is therefore dominant. Intervalley scattering is not important, since such scattering would, according to Harrison, 30 produce a stronger temperature dependence. Folland and Bassani $^{4}$ have, from an examination of the selection rules, shown that small intervalley scattering (relative to intravalley scattering) would be expected in $\mathrm{Mg}_{2} \mathrm{X}$ compounds near room temperature if the conduction band minima have a $x_{3}$ rather than $x_{1}$ symmetry. The band calculation of $\mathrm{Mg}_{2} \mathrm{Ge}$ by $\mathrm{Au}-\mathrm{Yang}$ and Cohen ${ }^{5}$ shows the conduction band minima to have $x_{3}$ symmetry which is consistent with our observation of small intervalley scattering.

Bardeen and Shockley 31 have given a formula for the mobility limited by acoustic mode scattering. When modifled for a many-valley semiconductor, ${ }^{32}$ the result is 


$$
\mu_{A}=\frac{(8 \pi)^{1 / 2}}{9} \frac{e t^{4} d v_{l}^{2}}{(k T)^{3 / 2}\left(E_{l c}\right)^{2}} \frac{\left(m_{l}^{*-1}+2 m_{t}^{*-1}\right)}{\left(m_{l}^{*} m_{t}^{* 2}\right)^{1 / 2}}
$$

In this equation $d$ is the density of the material and $v_{l}$ is the longitudinal sound velocity. For $M g_{2} G e, d$ is $3.10 \mathrm{~g} / \mathrm{cm}^{3}$ and $v_{l}$ is $6.2 \times 10^{5}$ $\mathrm{cm} / \mathrm{sec}$ according to Chung et al. $33^{\circ}$ our Hall mobility data at $300 \mathrm{~K}$ and Lee's effective masses ${ }^{2}$ give a deformation potential for the conduction band of $\left|E_{1 c}\right|=(18.7 \pm 0.9) \mathrm{eV}$. The deformation potential for the band gap $E_{1}$ may be estimated fairly well from the expression 34 $E_{1} \approx-B(\partial E / \partial P)_{T}$, where $B$ is the bulk modulus and $(\partial E / \partial P)_{T}$ is the pressure derivative of the band gap at constant temperature. For a cubic crystal ${ }^{35} B=\left(c_{11}+2 c_{12}\right) / 3$, and the elastic constants measured by chung et al. 33 give $B=5.46 \times 10^{11} \mathrm{dyn} / \mathrm{cm}^{2}$. A value of $\left|(\partial E / \partial P)_{T}\right|<5 \times 10^{-13} \mathrm{eV} \cdot \mathrm{cm}^{2} /$ dyn has been reported for $\mathrm{Mg}_{2} \mathrm{Ge}$ by Stella et al. 11 from the shift of the optical absorption edge with pressure. The maximum value of $E_{1}$ is thus estimated to be $0.27 \mathrm{eV}$. Since $\left|E_{1}\right|=\left|E_{1 c}\right|-\left|E_{I V}\right|$ if $E_{l c}$ and $E_{I V}$ have the same sign, 36 and experimentally we find that $\left|E_{\mid c}\right|$ is much greater than $\left|E_{1}\right|$ the deformation potentlals for the valence band $E_{1 V}$ and the conduction band $E_{I C}$ must have the same sign and nearly the same magnitude.

\section{B. Jonized Impurity Scattering}

As shown in Table 1, samples 1, 2, and 3.are undoped samples. Their impurity carrier concentration may arise from small variations in stoichiometry of $\mathrm{Mg}_{2} \mathrm{Ge}$, but direct determination of such smali 
changes in stoichiometry appears to be impossible. Even for the Al-doped samples it is not possible to determine $N_{D}$ directly from the atomic percent of aluminum which was added since there is a zonerefining effect during crystal growth which carries a substantial amount of the aluminum impurities to the top of the ingot. An attempt to determine the aluminum concentration with a mass spectrometer was not very successful. Interference from $\mathrm{MgH}$ and the high background level due to Mg were compllcating factors. The mass spectrographic analysis of $\mathrm{Mg}_{2} \mathrm{Ge}$ for impurities is shown in the Appendix (Table 5 ). For the nondegenerate samples 1-4 we can estimate the donor and acceptor concentrations $N_{D}$ and $N_{A}$ from the mobility curves (Figs. 4 and 5) between $50 \mathrm{~K}$ and $80 \mathrm{~K}$.

The maxima of the Hall mobilities of samples 3 and 4 were assumed to be $1 \mathrm{imited}$ by combinations of acoustic mode scattering and ionized impurity scattering. According to the Brooks-Herring 37 theory the mobility due to ionized impurity scattering is

$$
\mu_{1}=\frac{2^{7 / 2}(k T)^{3 / 2} \varepsilon_{0}^{2}}{\pi^{3 / 2} e^{3} m^{* 1 / 2}\left(n+2 N_{A}\right)}\left[\ln \left(\frac{6 m^{*}(k T)^{2} \epsilon_{0}}{\pi e^{2} \hbar^{2} n^{1}}\right)-1\right]^{-1},
$$

where $n^{\prime}=n+\left[1-\left(n+N_{A}\right) / N_{D}\right]\left(n+N_{A}\right)$. The expression

$$
\mu_{A 1}{ }^{-1}=\mu_{A}^{-1}+\mu_{1}^{-1}
$$




\section{THIS PAGE}

\section{WAS INTENTIONALLY \\ LEFT BLANK}


Fig. 5. The anomalous temperature deperidence of the Holl mobility of sample 2, which was found to be homogeneous in resistivity at $300 \mathrm{~K}$ but inhomogeneous at $77 \mathrm{~K}$. For temperatures greater than $300 \mathrm{~K}$ the mobility is limited only by acoustic mode scattering. For temperatures less than $200 \mathrm{~K}$ the moblility is 1 imited by a combination of acoustic mode scatter ing and space charge scattering. The anomalous hump in the mobility curve between $200 \mathrm{~K}$ and $300 \mathrm{~K}$ occurs in the transition region. 


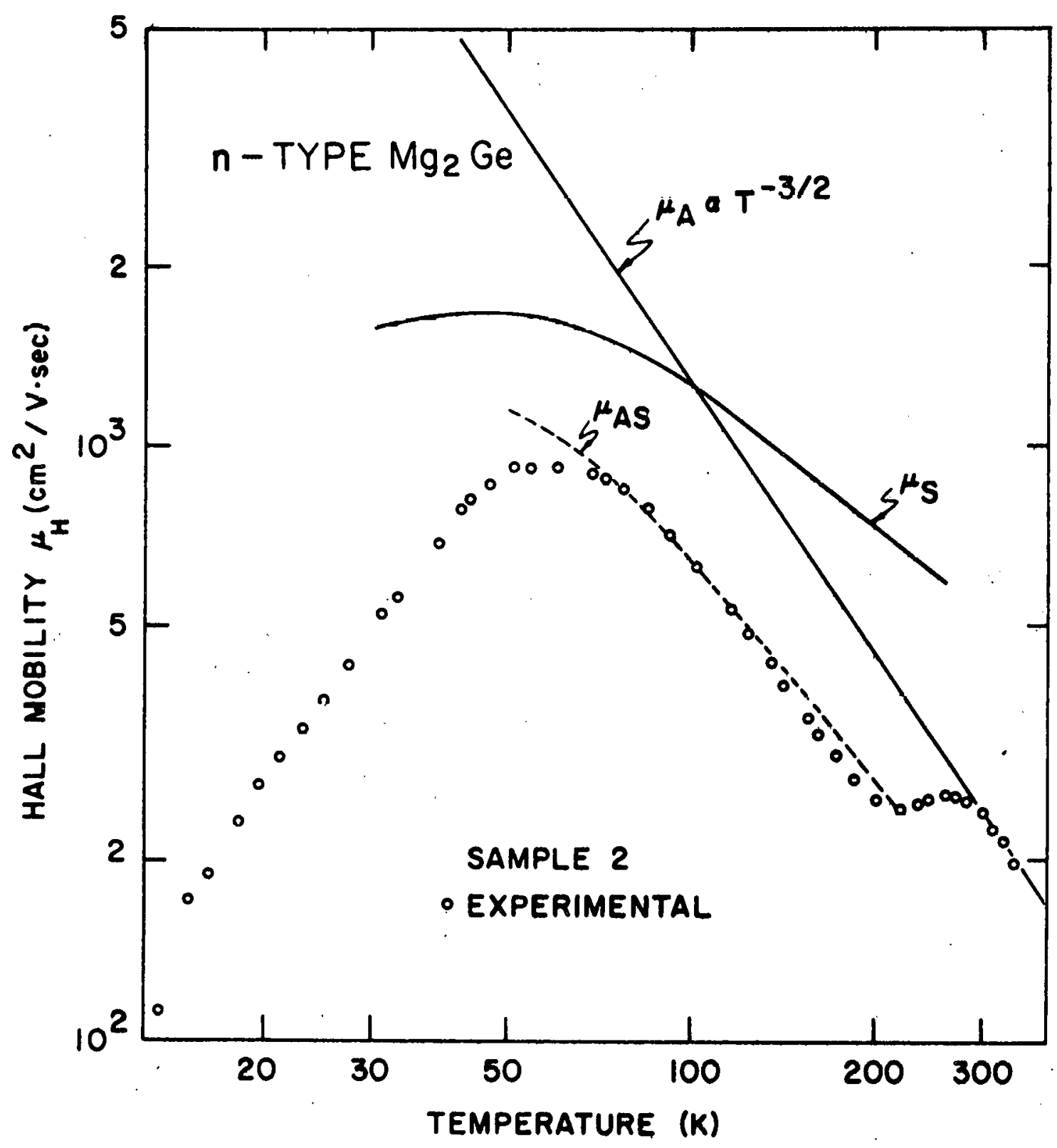


was used to fit the maxima of the Hall mobilities. Using Lee's effective masses ${ }^{2}$ and Eqs. (7) and (8), we determined $N_{D}$ and $N_{A}$ for samples 3 and 4. Values for $N_{D}$ are given in Table 1, and $N_{A}$ is the difference between $N_{D}$ and $n_{0}$. The donor and acceptor concentrations are comparable in magnitude.

\section{Neutral Impurity Scattering}

From Table 1 , we see that sample 1 has an ionization energy $\epsilon_{1}$ which is more than six times the ionization energy of any other sample. From Fig. 3, we observe that the number of charge carriers $n$ in sample 1 is small below $100 \mathrm{~K}$ and the number of neutral impurity centers $N_{N}=\left(N_{D}-N_{A}\right)-n$ is large. Neutral impurity scattering will therefore be important in sample 1 at temperatures below $100 \mathrm{~K}$. The expression obtained by Erginsoy 38 for the mobility due to neutral impurity scattering is

$$
\mu_{N}=e^{3 * *} / 20 n^{3} \varepsilon_{0} N_{N}
$$

where $m^{*}=\left(m_{l}^{*} m_{t}^{* 2}\right)^{1 / 3}$ is a mean effective mass. A composite result of mobility due to acoustic mode, ionized, and neutral impurity scatterings, obtained from the expression

$$
\mu_{A I N}^{-1}=\mu_{A}^{-1}+\mu_{1}^{-1}+\mu_{N}^{-1}
$$

was used to fit the mobility curve of sample 1 near the maximum $(60 \mathrm{~K})$. Using Lee's effective masses ${ }^{2}$ and Eqs. (7), (9), and (10), we obtained 
$N_{D}=8.4 \times 10^{16} \mathrm{~cm}^{-3}$ and $N_{A}=1.7 \times 10^{16} \mathrm{~cm}^{-3}$. In spite of its very high resistivity and Hall coefficient below $100 \mathrm{~K}$, sample 1 does not have an exceptionally high electron mobility owing to scattering of the electrons by neutral impurities.

\section{Space Charge Scattering}

Since space charge scattering owing to local inhomogenelties can greatly affect the mobility, ${ }^{39}$ the homogeneity of each sample must be taken into consideration when we analyze the Hall mobility data. Among these seven samples, only sample 2 showed marked inhomogeneity at $77 \mathrm{~K}$. The other samples were quite homogeneous, since the resistivities showed less that $10 \%$ variation along the length of each sample when measured either at $300 \mathrm{~K}$ or at $77 \mathrm{~K}$.

Sample 2 showed abnormal behavior in that it had a hump between $200 \mathrm{~K}$ and $300 \mathrm{~K}$ in its mobility curve (see Fig. 4 and 5). A test of the homogeneity of sample 2 was revealing. Although its resistivity varied less than $30 \%$ along the sample at $300 \mathrm{~K}$, its resistivity changed as much as an order of magnitude along the sample at $77 \mathrm{~K}$. As suggested by Weisberg ${ }^{39}$ the Hall mobility in semiconductors can be greatly reduced by inhomogeneous impurity distributions, owing to the formation of large space charge reglons surrounding the local inhomogcneitles. Fur the mobillty limited by space charge scattering he gives the equation

$$
\mu_{S}=A\left(n / n_{300}\right)^{1 / 3}(T / 300)^{-5 / 6} \text {, }
$$


where $n_{300}$ is the carrier concentration at $300 \mathrm{~K}$, and $\mathrm{n}$ is the carrier concentration at the temperature $T$. The constant $A$ must be determined experimentally for each particular position of the probes.

The mobility curve of sample 2 can be explained in the following way. For temperatures higher than $300 \mathrm{~K}$ the mobility is mainly limited by acoustic mode scattering. For temperatures below $200 \mathrm{~K}$ the inhomogeneity of the impurity distribution produces space charge scattering which must be added to the acoustic mode scattering. For $A=626 \mathrm{~cm}^{2} / \mathrm{V} \cdot \mathrm{sec}$, the mobility $\mu_{S}$ obtained from Eq. (II) for sample 2 is shown in Fig. 5." The combined contribution from acoustic mode scattering and space charge scattering, which is

$$
\mu_{A S}^{-1}=\mu_{A}^{-1}+\mu_{S}^{-1}
$$

gives a good fit to the experimental mobillty data from $200 \mathrm{~K}$ down to $70 \mathrm{~K}$ as shown in Fig. 5. The anomalous hump in the mobility curve between $200 \mathrm{~K}$ and $300 \mathrm{~K}$ occurs in the transition region. We see that space charge scattering is very important below $200 \mathrm{~K}$, but not important above $300 \mathrm{~K}$.

In FIg. 5, a composite mobility due to acoustic mode scattering, space charge scattering, and ionized Impurity scattering was used to fit the mobllity maximum of semple 2 from the expression

$$
\mu_{A S 1}^{-1}=\mu_{A S}^{-1}+\mu_{1}^{-1}
$$

From Eqs. (13) and (7), and Lee's effective masses, ${ }^{2}$ we found the donor 
concentration $N_{D}$ in sample 2 to be $1.4 \times 10^{16} \mathrm{~cm}^{-3}$. of all our samples, sample 2 had the lowest donor concentration. 


\section{MAGNETORESISTANCE}

\section{A. Theoretical Considerations}

For the past two decades the weak-field magnetoresistance of semiconductors has been studied extensively both experimentally and theoretically. For a cubic crystal in a weak magnetic field Pearson and $S u h 1^{40}$ have shown that the resistivity increment $\Delta \rho=\rho(H)-\rho(0)$ due to the presence of a magnetic field $\vec{H}$ is given by the equation

$$
\begin{gathered}
\Delta \rho / \rho_{0} H^{2}=b+c(\vec{T} \cdot \vec{H})^{2} / I^{2} H^{2}+d\left(I_{1}^{2} H_{1}^{2}+I_{2}^{2} H_{2}^{2}+I_{3}^{2} H_{3}^{2}\right) / I^{2} H^{2}, \\
\mu_{H} H \ll 10^{8},
\end{gathered}
$$

where the constants $b, c$, and $d$ are the magnetoresistance coefficients, $\rho_{0}$ is the zero-field resistivity, $\vec{r}$ is the current, and the subscripts 1, 2, 3 represent the three axes of the crystal. The Hall mobillty $\mu_{H}$ is measured in $\mathrm{cm}^{2} / \mathrm{V} \cdot \mathrm{sec}$, and the magnetic field $\mathrm{H}$ is measured in oersteds. Equation (14) applies only to crystals having point group symmetry $41 \mathrm{~m} 3 \mathrm{~m}, 432$, or $43 \mathrm{~m}$. ( $\mathrm{Mg}_{2} \mathrm{Ge}$ belongs to the point group $\left.\mathrm{m} 3 \mathrm{~m}.\right)$ If the direction cosines of $\vec{T}$ and $\vec{H}$ referred to the crystal axes are $i, j, k$, and $1, m, n$ then Eq. (14) becomes 40

$$
\Delta p / p_{0} H^{2}=b+c(i l+j m+k n)^{2}+d\left(i^{2} l^{2}+j^{2} m^{2}+k^{2} n^{2}\right) .
$$


For the special sample orientation shown in Fig. 1, the current vector $\vec{r}$ is along the direction [ii2], and the angle $\theta$, specifies the direction of $\vec{H}$ relative to [ii.2]. The direction cosines can then be specifled as $-1 / \sqrt{6},-1 / \sqrt{6}, 2 / \sqrt{6}$ for $\vec{\Gamma}$ and $(\sqrt{2} \sin \theta-\cos \theta) / \sqrt{6}$, $(\sqrt{2} \sin \theta-\cos \theta) / \sqrt{ } 6, \quad(\sqrt{2} \sin \theta+2 \cos \theta) / \sqrt{ } 6$ for $\vec{H}$. Equation (1.5) then becomes 42

$$
\begin{aligned}
\Delta \rho / \rho_{0} H^{2}=(12 b+6 c+5 d) / 12 & +(1 / 12)(6 c+d) \cos 2 \theta \\
& +(d / 3 / 2) \sin 2 \theta .
\end{aligned}
$$

Equation (16) allows all three magnetoresistance coefficients b, $c$, and $d$ to be obtained from the measurement of $\Delta \rho / p_{0} H^{2}$ as a function of the angle $\theta$,

In the many-valley model of a semiconductor, b, $c$, and $d$ depend on the Hall mobility $\mu_{H}$, the anisotropy parameter $K$, and the relaxation time $\tau$. All of these quantities depend upon the scattering mechanism. As suggested by Herring and Vogt, ${ }^{43}$ who take into account anisotropy in the scattering process, the main effects of scattering on the distribution function over each spheroidal constant energy surface can be described by two relaxation times, one transverse $T_{t}(\varepsilon)$ and one longitudinal $\tau_{\ell}(\varepsilon)$ to the axis of revolution of the spheroid. To simplify the analysis we assume 44 the relaxation times have the same dependence on energy 


$$
T_{l}=\tau_{l}^{0} T(\varepsilon) \text { and } T_{t}=\tau_{t}^{0} T(\varepsilon)
$$

The relaxation time anisotropy $K_{\tau} \equiv \tau_{l} / \tau_{t}-\tau_{l}^{0} / T_{t}^{0}$, whlch takes into account the possibility of anisotropy scattering, is then independent of energy. The anisotropy parameter $K$, which can be represented by the ratio of the mass anisotropy to the relaxation time anisotropy,

$$
K \equiv K_{m} / K_{T}=\left(m_{l}^{*} / m_{t}^{*}\right) /\left(\tau_{l}^{0} / \tau_{t}^{0}\right)
$$

is also independent of energy. Under these assumptions the coefficlents $b, c$, and $d$ for a cubic semiconductor, having $\langle 100\rangle$ type spherolds, are shown in Table $2 .^{15}$ Here $\left\langle\tau^{n}\right\rangle$ represents the Maxwellian average for the $n$th power of the relaxation tlme $T(\varepsilon)=\mu \epsilon^{p}$, where $\mu$ is a constant and $p$ is determined by the scattering mechanism. 45 The comprehensive review by Beer 44 gives the specific relationship of the coefficlents $b, c$, and $d$ to the symmetry of the constant energy spherolds in the Brlllouin zone.

$$
\begin{aligned}
& \text { Spherical symmetry: } b+c=0, d=0 \\
& \langle 100\rangle \text { type spheroids: } b+c+d=0, d<0 \\
& \langle 111\rangle \text { type spheroids: } b+c=0, d>0 \\
& \langle 110\rangle \text { type spheroids: } b+c-d=0, d>0
\end{aligned}
$$

Therefore, a determination of the coefficients $b, c$, and $d$ allows us to obtain the orientation of the constant energy spheroids in a manyvalley semiconductor. 
Table 2. Magnetoresistance coefficients in terms of the Hall mobility, anisotropy parameter, and relaxation time for $\langle 100\rangle$ type constant energy spheroids. 15

Magnetoresistance Coefficients For $\langle 100\rangle$ Type Spheroids

b

$$
\mu_{H}^{2}\left[\frac{\langle\tau\rangle\left\langle\tau^{3}\right\rangle}{\left\langle\tau^{2}\right\rangle^{2}} \frac{(2 K+1)\left\langle K^{2}+K+1\right)}{K(K+2)^{2}}-1\right]
$$

c

$$
\mu_{H}^{2}\left[1-\frac{\langle\tau\rangle\left\langle\tau^{3}\right\rangle}{\left\langle\tau^{2}\right\rangle^{2}} \frac{3(2 K+1)}{(K+2)^{2}}\right]
$$

d

$-\mu_{H}^{2} \cdot \frac{\langle\tau\rangle\left\langle\tau^{3}\right\rangle}{\left\langle\tau^{2}\right\rangle^{2}} \cdot \frac{(2 K+1)(K-1)^{2}}{K(K+2)^{2}}$ 
Dimensionless Seitz coefficients have been suggested by Allgaier 46 in order to simplify the comparison of results when one uses different samples, different temperatures or different semiconductors. Table 2 shows that the square of the mobility $\mu_{H}^{2}$ is a common factor of the magnetoresistance coefficients $b, c$, and $d$. We can, therefore, write Eq. (15) in the form

$$
\begin{aligned}
\left(\Delta \rho / \rho_{0}\right) /\left(\mu_{H} H / C\right)^{2}= & b^{\prime}+c^{\prime}(i 1+j m+k n)^{2} \\
& +d^{\prime}\left(i^{2} l^{2}+j^{2} m^{2}+k^{2} n^{2}\right),
\end{aligned}
$$

where $c=10^{8} \mathrm{~cm}^{2} 0 \mathrm{e} / \mathrm{V} \cdot \mathrm{sec}$ and $b^{\prime}, c^{\prime}$, and $d^{\prime}$ are now the dimensionless Seitz coefficients.

In compound semiconductors, it is highly desirable to use a single sample to obtain all three coefficients b, $c$, and $d$. Otherwise slight variations in stoichlometry and nonuniform distributions of impurities, which occur from one sample to another, will produce different values of $\mu_{H}$ and make the interpretation of the data difficult. Also, magnetoresistance measurements are very sensitive to inhomogeneities as pointed out by Herring 47 and by Bate et al. 48 For these reasons, we have used just one sample at each impurity concentration to determine the coefficients $b, c$, and $d$; and we have carefully checked the homogeneity of all samples not only at $300 \mathrm{~K}$ but also at $77 \mathrm{~K}$. 


\section{B. Results and Analysis}

The magnetic field dependence up to $8 \mathrm{kOe}$ of both the longitudinal $(\vec{T} \| \vec{H})$ and transverse $(\vec{T} \vec{H})$ magnetoresistance $\Delta \rho / p_{0}$ was determined for all seven samples at $77.4 \mathrm{~K}$. Sample 4 was also measured at $43.6 \mathrm{~K}$. As shown in Fig. 6, both the longitudinal and transverse effects for each sample show the normal $\mathrm{H}^{2}$ dependence as expected in weak magnetic fields $\left(\mu_{H} H \ll 10^{8}\right)$. A much higher magnetic field strength would be required to violate the weak-field inequality, since the maximum value of $\mu_{H}$ for our samples is only $2.5 \times 10^{3} \mathrm{~cm}^{2} / \mathrm{V} \cdot \mathrm{sec}$.

The quantity $\Delta p / \rho_{0} H^{2}$ was measured as a function of the angle $\theta$ for seven homogeneous $n$-type $\mathrm{Mg}_{2}$ Ge samples at $77.4 \mathrm{~K}$. The data are shown in Figs. 7 and 8 . Since the typical value of the magnetoresistance $\Delta p / p_{0}$ is about $10^{-3}$ for our samples, and the zero-field resistivity. $\rho_{0}$ is very sensitive to variations in temperature, it was important to keep the sample temperature stable. Therefore, the magnetoresistance effect was measured at several stable temperatures by using sultable refrigerants. Liquid nitrogen was excellent for one such temperature. Liquid hellum was not satisfactory because of Impurity band conduction at this temperature. Besides liquid nitrogen temperature and room temperature, a stable temperature at $194.5 \mathrm{~K}$ was provided by dry ice In acetone, and a fairly stable temperature at $43.6 \mathrm{~K}$ by pumping on liquid nitrogen. For sample 4 we measured $\Delta \rho / p_{0} H^{2}$ versus $\theta$ at these four stable temperatures. The results are shown in Fig. 8. From the angular dependence of $\Delta \rho / \rho_{0} H^{2}$ shown in Figs. 7 and 8 , the magnetoresistance coefficients $b, c$, and $d$ for each sample 
THIS PAGE

WAS INTENTIONALLY

LEFT BLANK 
Fig. 6. The longitudinal and transverse magnetoresistance $\Delta \rho / p_{0}$
of seven samples of $M g_{2} G$, which show the normal $\mathrm{H}^{2}$ magnetic field dependence for $H$ up to $8 \mathrm{k}$ le. The symbol $L$ represents longitudinal $(\vec{T} \| \vec{H})$ and the symbol $T$ represents transverse $(\overrightarrow{!}, \vec{H})$. magnetores istance. 


\section{7}

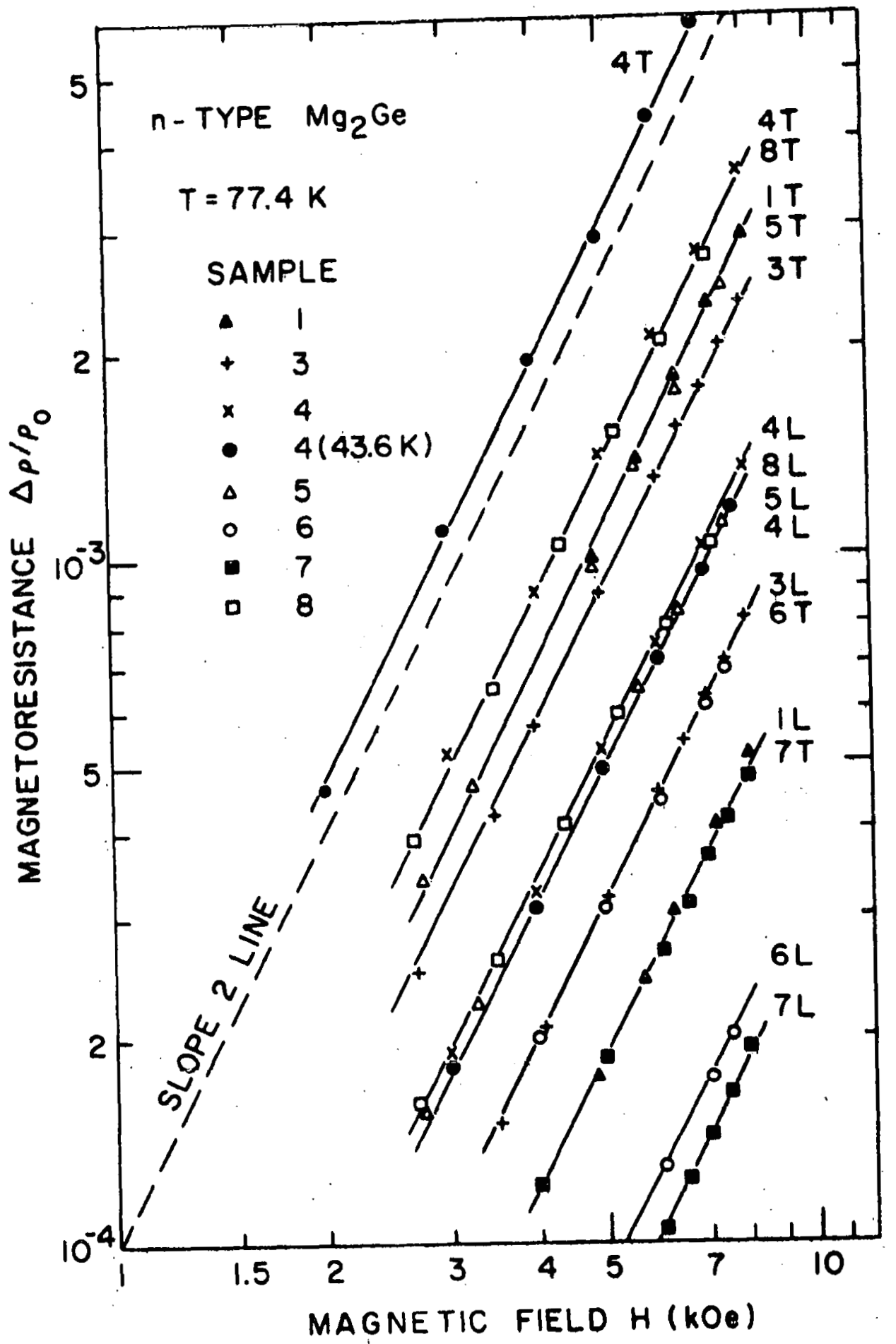


THIS PAGE

\section{WAS INTENTIONALLY LEFT BLANK}


Fig. 7. The magnetoresistance effect in $\mathrm{Mg}_{2} \mathrm{Ge}$ showing the angular dependence of $\Delta \rho / \rho_{0} H^{2}$ at $77 \mathrm{~K}$. For each sample $\Delta_{\rho} / p_{0} H^{2}$ is described by $E q .\left({ }^{6}\right)$, and a set of magnetoresistance coefficlents $b, c$, and $d$ can be obtained from each curve. since $b+c+d=0$ and $d<0$. we conclude that $n$-type $\mathrm{Mg}_{2} \mathrm{Ge}$ is a many-valley semiconductor with constant energy spherolds in the $\langle 100\rangle$ directlons. 


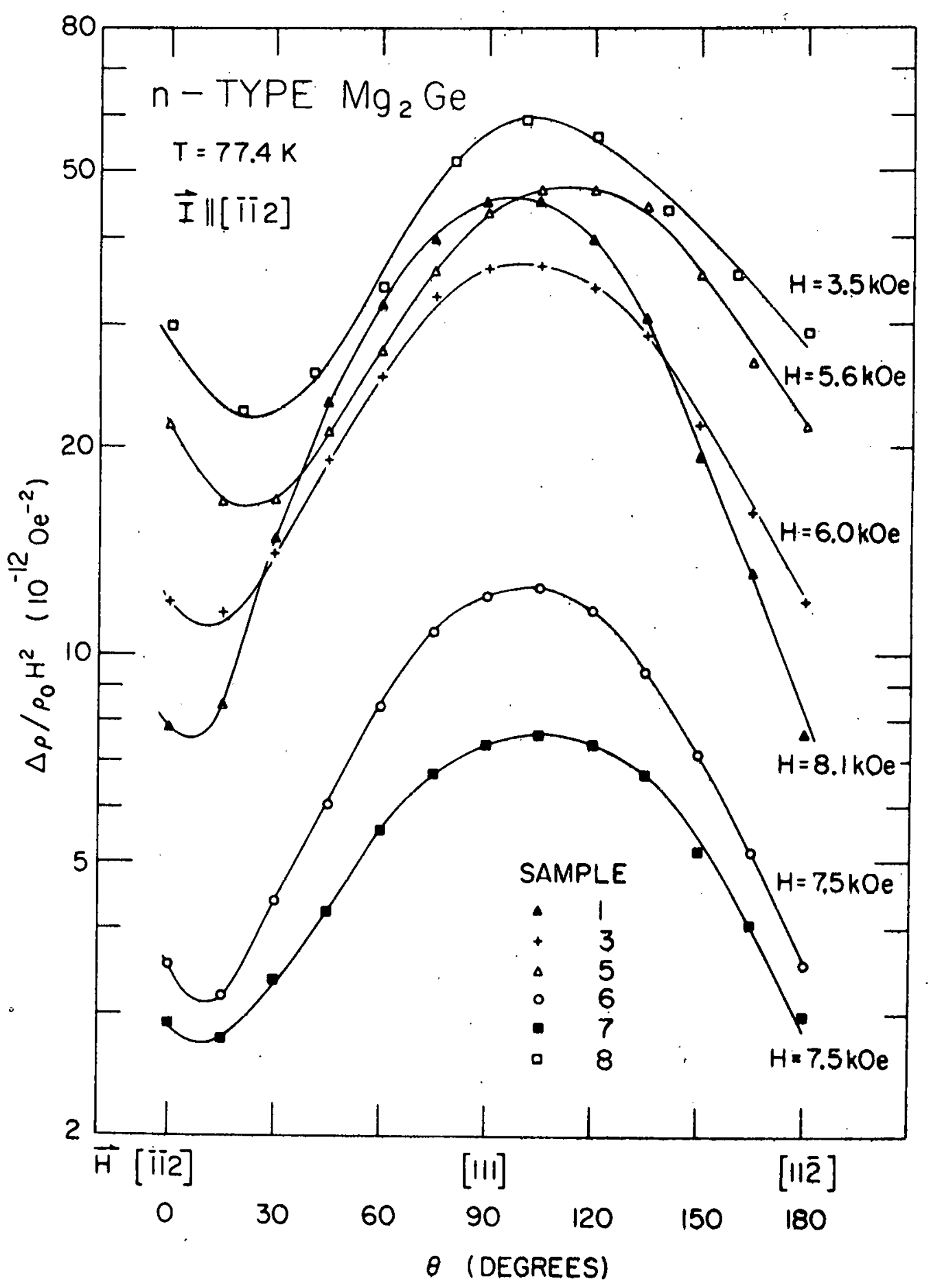


THIS PAGE

WAS INTENTIONALLY

LEFT BLANK 
Fig. 8. The magnetoresistarice effect in $\mathrm{Mg}_{2} \mathrm{Ge}$ showing the angular dependence of $\Delta \rho / \mathrm{p}_{0} \mathrm{H}^{2}$ for sample 4 at four stable temperatures. The symmetry condition for $\langle 100\rangle$ type spherolds is satisfied at all four temperatures. The values of the anisotropy parameter $K$ were found to decrease from 2.13 at $299.5 k$ to 1.65 at $43.6 \mathrm{~K}$. 
41

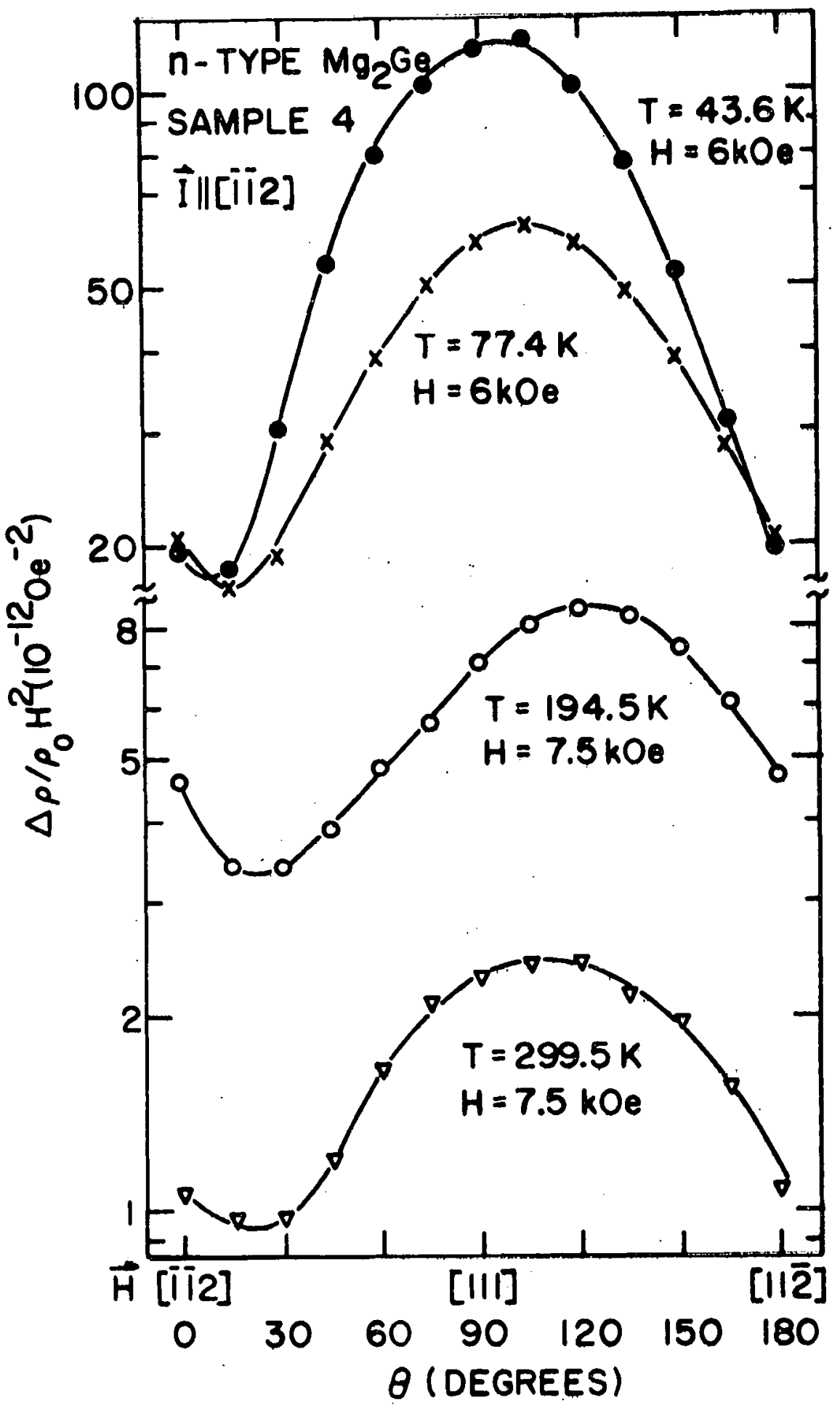


were determined. A computer was used to minimize the rms deviation from Eq. (16). Values for b, $c$, and $d$ are shown in Table 3.

The coefficients $b, c$, and d satisfy the symmetry condition $b+c+x d=0, d<0$ with $x=1$. As shown In Table 3, the value of $x$ varied from 0.900 to 1.09 . In all samples, therefore, $x$ was within 10 percent of the theoretical value $x=1$. The condition for $\langle 100\rangle$ type spheroids is weil satisfied for all samples at $77.4 \mathrm{~K}$ and for sample 4 also at $43.6 \mathrm{~K}, 194.5 \mathrm{~K}$ and $299.5 \mathrm{~K}$. This result confirms the theoretical predictions of Lee, ${ }^{2}$ Folland and Bassani, 4 and Au-Yang and Cohen $^{5}$ that the conduction band minima of $\mathrm{Mg}_{2} \mathrm{Ge}$ consist of a set of constant energy spheroids along the $\langle 100\rangle$ directions in the Brillouin zone.

For $\langle 100\rangle$ type spheroids we can obtain the anisotropy parameter $K$ from Table 2 by eliminating the factor $\langle\tau\rangle\left\langle\tau^{3}\right\rangle /\left\langle\tau^{2}\right\rangle^{2}$

$$
\frac{2(k-1)^{2}}{k^{2}+k+1}=\frac{b+c-d}{b+\mu_{H}^{2}}
$$

From Eq. (21) and the values of $b, c, d$, and $\mu_{H}$ in Table 3 we determined K. The values for our seven samples are given in Table 3.

For each value of $K$ the scattering factor $\langle\tau\rangle\left\langle\tau^{3}\right\rangle /\left\langle\tau^{2}\right\rangle^{2}$ (see Table 2) was computed from the values of $\mu_{H}$ and $b, \mu_{H}$, and $c$, and $\mu_{H}$ and $d$ listed in Table 3. These three values for each scattering factor were always within 3 percent of the average value which is given in the last column of Table 3. 
THIS PAGE

\section{WAS INTENTIONALLY \\ LEFT BLANK}


Table 3. The magnetoresistance coefficients $b, c$, and $d$, the dimensionless Seitz coefficients, $b^{\prime}, c^{\prime}$, and $d^{\prime}$, the anisotropy parameter $K$, and the scattering factor $\langle\tau\rangle\left\langle\tau^{3}\right\rangle /\left\langle\tau^{2}\right\rangle^{2}$ of $n$-type $\mathrm{Mg}_{2} \mathrm{Ge}$.

\begin{tabular}{|c|c|c|c|c|c|c|c|}
\hline $\begin{array}{c}\text { Sample } \\
\text { No. }\end{array}$ & $\begin{array}{c}T \\
(K)\end{array}$ & $\left(10^{2} \mathrm{~cm}^{-\mathrm{R}^{3}} / \mathrm{C}\right)$ & $10^{-2} \rho_{0}^{\rho_{0}}$ & $2^{2} \mathrm{~cm}^{2} / V$ & b & $10^{-12} 0$ & d \\
\hline 1 & 77.4 & 199.0 & 1250.0 & 15.9 & 50.7 & -34.5 & -16.4 \\
\hline 3 & 77.4 & 7.64 & 60.2 & 12.7 & 42.7 & -20.8 & -20.2 \\
\hline \multirow[t]{4}{*}{4} & 43.6 & 3.45 & 16.3 & 21.2 & 132.0 & -88.8 & -48.0 \\
\hline & 77.4 & 1.95 & 8.71 & 22.4 & 73.7 & -30.6 & -45.3 \\
\hline & 194.5 & 1.57 & 23.1 & 6.80 & 12.3 & -2.81 & -9.44 \\
\hline & 299.5 & 1.48 & 47.2 & 3.14 & 2.91 & -0.74 & -2.07 \\
\hline 5 & 77.4 & 0.834 & 3.74 . & 22.3 & 58.5 & -14.2 & -46.8 \\
\hline 6 & 77.4 & 0.174 & 1.74 & 10.0 & 14.5 & -7.34 & -7.30 \\
\hline 7 & 77.4 & 0.0996 & 1.36 & 7.32 & 9.14 & -3.64 & -5.06 \\
\hline 8 & 77.4 & 2.84 & 12.0 & 23.7 & 69.4 & -19.5 & -46.7 \\
\hline
\end{tabular}




\begin{tabular}{cccccccc}
\hline \hline$x$ & $b^{\prime}$ & $c^{\prime}$ & $d^{\prime}$ & \multicolumn{2}{c}{$k$} & \multicolumn{2}{c}{$\langle\tau\rangle\left\langle\tau^{3}\right\rangle\left\langle\left\langle\tau^{2}\right\rangle^{2}\right.$} \\
& & & & prolate oblate & prolate & oblate \\
\hline 0.988 & 0.201 & -0.137 & -0.065 & 1.51 & 0.664 & 1.16 & 1.16 \\
1.08 & 0.265 & -0.129 & -0.125 & 1.78 & 0.560 & 1.17 & 1.15 \\
0.900 & 0.295 & -0.198 & -0.107 & 1.65 & 0.606 & 1.26 & 1.24 \\
0.951 & 0.147 & -0.061 & -0.090 & 1.64 & 0.610 & 1.10 & 1.09 \\
1.01 & 0.266 & -0.061 & -0.204 & 2.10 & 0.475 & 1.14 & 1.11 \\
1.05 & 0.296 & -0.075 & -0.211 & 2.13 & 0.470 & 1.16 & 1.12 \\
0.946 & 0.118 & -0.029 & -0.094 & 1.67 & 0.599 & 1.07 & 1.06 \\
0.981 & 0.145 & -0.073 & -0.073 & 1.56 & 0.640 & 1.11 & 1.09 \\
1.09 & 0.170 & -0.068 & -0.094 & 1.68 & 0.595 & 1.09 & 1.08 \\
1.05 & 0.124 & -0.035 & -0.083 & 1.63 & 0.611 & 1.07 & 1.05 \\
\hline \hline
\end{tabular}


The scattering factor is always greater than one as required by the Schwortz inequality $\langle\tau\rangle\left\langle\tau^{3}\right\rangle /\left\langle\tau^{2}\right\rangle^{2} \geq 1$. Our experimental values, whlch vary from 1.05 to 1.26 , have very reasonable magnitudes. The theoretical values are 1.27 for acoustical mode scattering, 1.00 for neutral impurlty scattering, and 1.58 for ionized impurity scattering.

In solving for $K=K_{m} / K_{T}$ we assumed the constant energy surfaces were prolate $(K>1)$ rather than oblate $(K<1)$, since the theoretical value for $K_{m}$ from Table 1 of Lee's paper ${ }^{2}$ is 2.52 and the value of $K_{T}$ according to Fig. 12 of Herring's paper $^{49}$ is probably not far from one when intravalley acoustic mode scattering is dominant. At $77 \mathrm{~K}$ the values of $K$ for our samples ranged from 1.51 to 1.78 . The $K$ values for $\mathrm{Mg}_{2} \mathrm{Ge}$ are smaller than the $\mathrm{K}$ values for some other semiconductors such as $n$-type $G e(K \approx 8$ at $77 K)$ reported by Laff and Fan, 50 n-type SI ( $K=4.6$ at $68 \mathrm{~K}$ ) measured by Pearson and Herring, 51 $n$-type SI ( $K=5.2$ at $80 \mathrm{~K}$ ) measured by Broudy and Venables, 52 and $n$-type $\mathrm{Mg}_{2} \mathrm{Sn}(\mathrm{K}=2.8$ to 3.53 at $77 \mathrm{~K}$ ) determined by Umeda. 9

At $77 \mathrm{~K}$ the value of $\Delta p / p_{0} H^{2}$ in $M g_{2} G e$ is quite small for a semiconductor. It is abnut the same order of magnitude as that observed for indlum oxide by Weiher and Dick. 53 it is about one order of magnitude smaller than $\Delta p / \rho_{0} H^{2}$ observed by Umeda ${ }^{9}$ in $\mathrm{Mg}_{2} \mathrm{Sn}$, and about two orders of magnitude smaller than $\Delta \rho / \rho_{0} H^{2}$ observed in Ge by Pearson and Suhl. 40 The small magnetoresistance effect in $\mathrm{Mg}_{2} \mathrm{Ge}$ is the result of small Hall mobility $\mu_{H^{*}}$. In fact, if we look at the dimensionless Seitz coefficients, related to $\left(\Delta \rho / p_{0}\right) /\left(\mu_{H} H / C\right)^{2}$ by Eq. (20), we see values which are comparable to those of other 
semiconductors such as PbTe (Allgaier ${ }^{46}$ ) or SrTiO $_{3}$ (Frederikse et al. ${ }^{54}$ ). Also these coefficients $b^{\prime}, c^{\prime}, d^{\prime}$ (as shown in Table 3) are not very different for different samples or different temperatures. This uniformity suggests that our data are consistent and reliable. The anisotropy parameter $K$ for sample 4 was obtained at the four temperatures $299.5 \mathrm{~K}, 194.5 \mathrm{~K}, 77.4 \mathrm{~K}$, and $43.6 \mathrm{~K}$.' The results are shown in Table 3. The value of $K=K_{m} / K_{T}$. decreased from 2.13 at $300 \mathrm{~K}$ to 1.65 at $43.6 \mathrm{~K}$. This decrease. is to be expected, as emphasized by Laff and Fan, 49 since scattering by ionized impurities becomes more important at lower temperatures. $\mathrm{Mg}_{2} \mathrm{Ge}$ does not have a small direct energy gap?, 12 and thus the shape of the spheroids can not be very sensitive to temperature. Hence $K_{m}$ should be nearly constant. The decrease in $K$, therefore, means an increase in $K_{\tau^{*}}$. If we assume $K_{\tau}$ at $300 . K$ to be approximately one, since intravalley acoustic mode scattering is dominant at this temperature, then $K_{\tau}$ at $43.6 \mathrm{~K}$ is 1.29. Also $k_{m}$ at $300 k$ would be about 2.1 which is not greatly different from the theoretical estimate of 2.5 by Lee. ${ }^{2}$ our value is cortainly a rough estimate and Lee's value depends upon his effective masses which are uncertain because the symmetiry of the conduction band minima is $X_{3}$, as predicted by Au-Yang and Cohen ${ }^{5}$ and concluded from our Hall mobility temperature dependence, rather than $x_{1}$ as calculated by Lee. ${ }^{2}$

Figure 9 shows $\Delta \rho / \rho_{0} H^{2}$ versus $\theta$ at $77 \mathrm{~K}$ for three inhomogeneous n-type $\mathrm{Mg}_{2} \mathrm{Ge}$ samples. Our resistivity tests for these samples at $77 \mathrm{~K}$ revealed variations in resistivities greater than a factor of 2 along 


\section{THIS PAGE}

\section{WAS INTENTIONALLY \\ LEFT BLANK}


Flg. 9. The magnetoresistance effect of $\mathrm{Mg}_{2} \mathrm{Ge}$ showing the angular dependence of $\triangle P / \mathrm{POH}^{2}$ at $77 \mathrm{~K}$ for three inhomogeneous samples. Values of $\triangle \rho / \mathrm{pOH}^{2}$ are about an order of magnitude higher than the values for homogeneous samples shown in $\mathrm{F} / \mathrm{g} .7 . \Delta \rho / \rho_{0} \mathrm{H}^{2}$

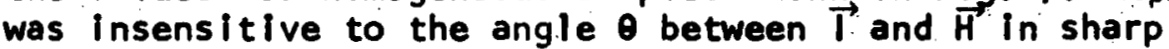
contrast to the effects observed with homogeneous samples (Figs. 7 and 8 ). 


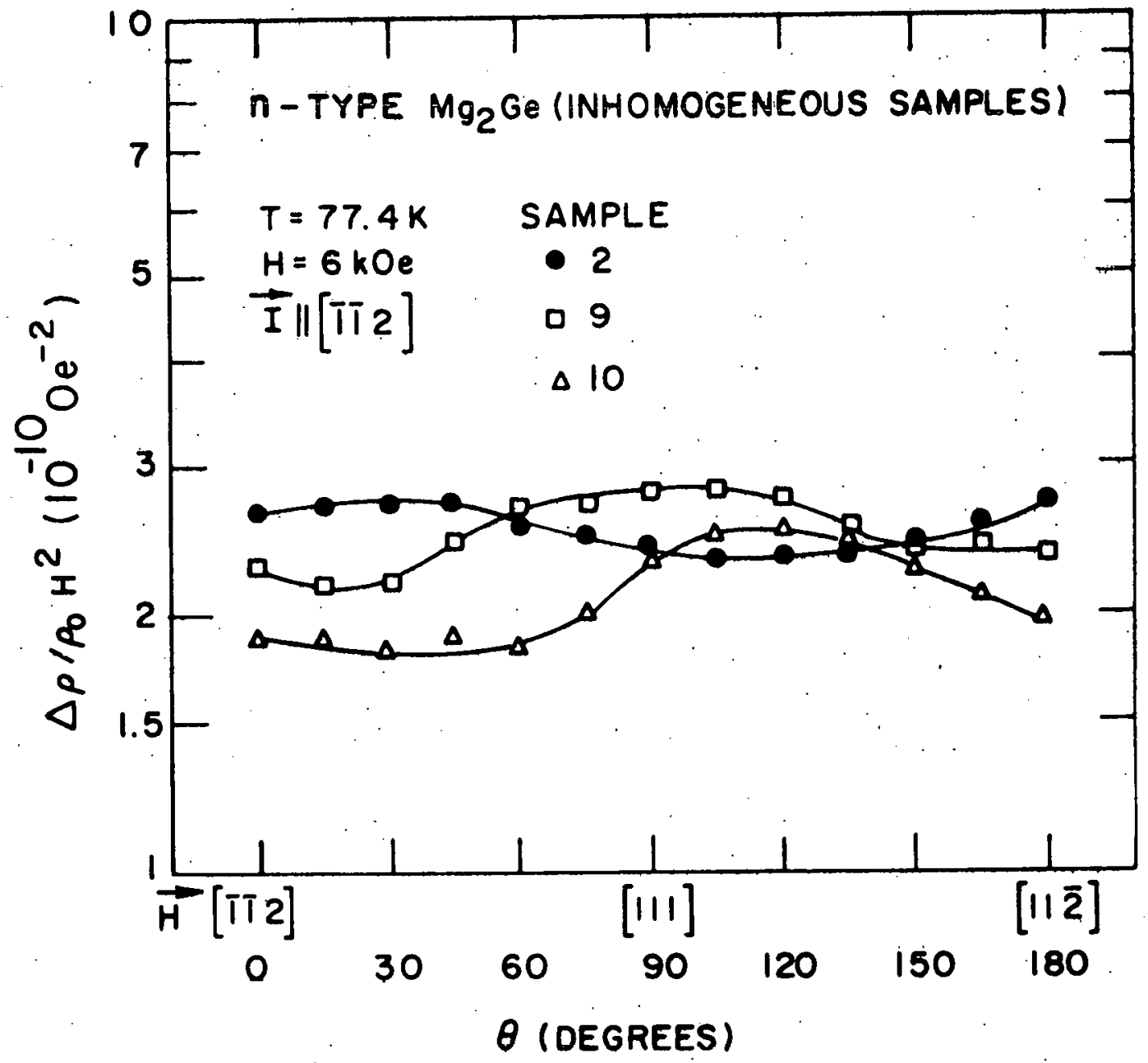


each sample. $\Delta \rho / \rho_{0} \mathrm{H}^{2}$ at $77 \mathrm{~K}$ for these samples is about an order of magnitude higher than for our homogeneous samples. This result is not too surprising, since an anomalously high magnetoresistance effect for inhomogeneous samples of InSb has been observed by Bate et al. ${ }^{48}$ The Hall mobility at $77 \mathrm{~K}$ for these inhomogeneous samples 2,9 , and 10 is $8.6 \times 10^{2} \mathrm{~cm}^{2} / \mathrm{cmV} \cdot \mathrm{sec}, 2.2 \times 10^{3} \mathrm{~cm}^{2} / \mathrm{V} \cdot \mathrm{sec}$, and $2.5 \times 10^{3}$ $\mathrm{cm}^{2} / \mathrm{V} \cdot \mathrm{sec}$, respectively. Despite the large differences in Hall mobility of these samples the magnetoresistances are practically the same. Also, $\Delta \rho / \rho_{0} H^{2}$ is insensitive to the angle $\theta$, in sharp contrast to the results for our homogeneous samples shown in Figs. 7 and 8 , where the values of $\Delta \rho / \rho_{0} H^{2}$ are quite sensitive to the angle $\theta$ and to the Hall mobility $\mu_{H}$. These facts imply that Eq. (16) can not be applied to these inhomogeneous samples. In homogeneous samples give anomalous magnetoresistance effects and should not be used to determine the electronic structure of a semiconductor: 


\section{CONCLUSIONS}

Weak-field magnetoresistance measurements have been made on homogeneous single crystals of $n$-type $\mathrm{Mg}_{2} \mathrm{Ge}$. Our results confirm the theoretical prediction that $n$-type $\mathrm{Mg}_{2} \mathrm{Ge}$ is a many-valley semiconductor with constant energy spheroids in the $\langle 100\rangle$ directions. The Hall mobility of our samples from $150 \mathrm{~K}$ to $300 \mathrm{~K}$ had a $T^{-3 / 2}$ temperature dependence, which indicates that intravalley acoustic mode scattering is the dominant scattering mechanism in this temperature range and that the symmetry of the conduction band minima is $x_{3}$ rather than $x_{1}$. The anisotropy parameter $K=K_{m} / K_{\tau}$ was found to be about 2.1 at $300 \mathrm{~K}$. If we assume the relaxation time anisotropy $K_{\tau}$ to be approximately one at $300 \mathrm{~K}$, since intravalley acoustic mode scattering is dominant at this temperature, the effective mass ratio $k_{m}$ will also be about 2.1. This $K_{m}$ value is not greatly different from the theoretical estimate ${ }^{2}$ of 2.5 .

We have carefully checked the homogeneity of each sample at $300 \mathrm{~K}$ and $77 \mathrm{~K}$. In homogeneous samples showed anomalies in the Hall mobility temperature dependence, and also showed higher magnetoresistance. Values of $\triangle \rho / \rho_{0} H^{2}$ were insensitive to the Hall mobility and to the angle between $\vec{T}$ and $\vec{H}$ in sharp contrast to the effects observed with homogeneous samples.

It would be desirable to make piezoresistance measurements on $\mathrm{Mg}_{2}$ Ge. A combination of such measurements with our values of the anisotropy parameter could yield the deformation potential $\Xi_{u^{\circ}} 8$ 
The piezoresistance effect will probably be smaller for $\mathrm{Mg}_{2} \mathrm{Ge}$ than for $\mathrm{Mg}_{2} \mathrm{Sn}$ due to the smaller $\mathrm{K}$ value for $\mathrm{Mg}_{2} \mathrm{Ge}$. It might also be desirable to study the magnetoresistance and piezoresistance of $\mathrm{p}$-type $\mathrm{Mg}_{2} \mathrm{Ge}$ since little experimental data are available on the electronic structure of p-type meterial. 


\section{LITERATURE CITED}

1. R. D. Redin, R. G. Morris, and G. C. Danielson, Phys. Rev. 109, 1916 (1958).

2. P. M. Lee, Phys. Rev. 135, All10 (1964).

3. N. 0. Folland, Phys. Rev. 158, 764 (1967).

4. N. 0. Folland and F. Bassani, J. Phys. Chem. Solids 29, 281 (1968).

5. M. Y. Au-Yang and M. L. Cohen, Phys, Rev, 178, 1358 (1969).

6. J. P. Van Dyke and F. Herman, Phys. Rev. B 2, 1644 (1970).

7. W. B. Whitten and G. C. Danielson, in Proceedings of the Seventh International Conference on the Physics of Semiconductors, edited by M. Hulin (Dunod, Paris, 1964), p. 537.

8. L. D. Crossman and G. C. Danielson, Phys. Rev. 171, 867 (1968).

9. J. Umeda, J. Phys. Soc. Japan 19, 2052 (1964).

10. G. A. Stringer and R. J. Higgins, J. Appl. Phys. 41,489 (1970).

11. A. Stella, A. D. Brothers, R. H. Hopkins, and D. W. Lynch, Phys. Status Solidi 23, 697 (1967).

12. L. A. Lott and D. W. Lynch, Phys. Rev. 141, 681 (1966).

13. D. H. Grotzky and P. H. Sidles, USAEC Report No. 1S-2100, July, 1969, P. P-53 (unpublished).

14. R. G. Schwartz, H. Shanks, and B. C. Gerstein, J. Solid State Chem. 3, 533 (1971).

15. M. Glicksman, in Progress in Semiconductors, edited by A. F. Gibson et al. (WITey, New York, 1958), Vol. 3, pp. 3-25.

16. S. N. Lee, Ph. D. thes is (lowa State University, 1968) (unpublished).

17. F. R. Kroeger and W. A. Rhinehart, Rev. Scl. Instr. 42, 1532 (1971).

18. H. Fritzsche, Phys. Rev. 29, 406 (1955).

19. A. Millẹr and E. Abrahams, Phys. Rev. 120, 745 (1960). 
20. N. F. Mott and W. D. Twose, Advan. Phys. 10, 107 (1961).

21. H. Nishimura, Phys. Rev. 138, A815 (1965).

22. E. A. Davis and W. D. Compton, Phys. Rev. 140, A2183 (1965).

23. H. Brooks, in Advances in Electronics and Electron Physics, Vol. VII, edited by L. Marton (Academic, New York, 1955), pp. 102-104.

24. D. McWlllilams and D. W. Lynch, Phys. Rev. 130, 2248 (1963).

25. T. N. Morgen, Phys. Rev. 139, A343 (1965).

26. C. S. Hung and J. R. Gllessman, Phys, Rev. 96, 1226 (1954).

27. E. M. Conwell, Phys. Rev. 103, 51 (1956).

28. H. C. Casey, Jr., F. Ermanis, and K. B. Wolfstirn, J. Appl. Phys. 40, 2945 (1969).

29. R. P. Khosla, Phys. Rev. 183, 695 (1969).

30. W. A. Harrison, Phys. Rev. 104, 1281 (1956).

31. J. Bardeen and W. Shockley, Phys. Rev. 80,72 (1950).

32. R. A. Smith, Semiconductors (Cambridge U.P., Cambridge, England, 1961), P. 147.

33. P. L. Chung, W. B. Whitten, and G. C. Danielson, J. Phys. Chem. Solids $\underline{26}, 1753$ (1965).

34. E. Ehrenreich, Phys. Rev. 120, 1951 (1960).

35. C. Kittel, Introduction to Solid State Physics (Wiley, New York, 1967), 3rd od., p. 118.

36. W. Shockley, Electrons and Holes in Semiconductors (Van Nostrand, New York, 1950), p. 270.

37. F. J. Blatt, in Solld State Physics, Vol. 4, edited by F. Seltz and D. Turnbull (Academic, New York, 1957), p. 344.

38. C. Erginsoy, Phys. Rev. 29, 1013 (1950).

39. L. R. Weisberg, J. Appl. Phys. 33, 1817 (1962).

40. G. L. Pearson and H. Suh1, Phys. Rev. 83, 768 (1951). 
41. A. C. Beer, Solid State Physics - Supplement 4, edited by F. Seitz and D. Turnball (Academic, New York, 1963), P. 44.

42. This equation is identical to Eq. (12) of. J. Umeda, J. Phys. Soc. Japan 19, 2052 (1964), except for a change in sign of the coefficlent of $\cos 2 \theta$ owing to the difference in our definition of the angle $\theta$.

43. C. Herring and E. Vogt, Phys. Rev. 101, 944 (1955).

44. A. C. Beer, Solid State Physics - Supplement 4, edited by F. Seitz and D. Turnball (Academic, New York, 1963), Pp. 229-231.

45. A. H. Wilson, Theory of Metals (Cambridge U. P., Cambridge, England, 1953), 2nd ed., P. 240.

46. R. S. Allgaler, Phys. Rev. 119, 554 (1960).

47. C. Herring, J. Appl. Phys. 31, 1939 (1960).

48. R. T. Bate, J. C. Bell, and A. C. Beer, J. Appl. Phys. 32, 806 $(1960)$.

49. C. Herring, Bell System Tech. J. 34, 237 (1955), Appendix A.

50. R. A. Laff and H. Y. Fan, Phys. Rev. 112, 317 (1958).

51. G. L. Pearson and C. Herring, Physica 20, 975 (1954).

52. R. M. Broudy and J. D. Venables, Phys. Rev. 105, 1757 (1957).

53. R. L. Weiher and B. G. Dick, Jr., J. Appl. Phys. 35, 3511 (1964).

54. H. P: R. Frederikse, W. R. Hosler, and W. R. Thurber, Phys. Rev. 143, 648 (1966). 


\section{ACKNOWLEDGMENTS}

The author wishes to thank Dr. G. C. Danielson for gulding this research. The author also wishes to thank Mr. P. H. Sidles and Mr. H. R. Shanks for several helpful discussions and Mr. O. M. Sevde and Mr. P. A. Millis for technical assistance. The mass spectrographic analys Is was carried out by Mr. R. J. Conzemius of Professor H. J. Sevc's physical chemistry group in the Ames Laboratory. 
XI. APPEND IX 
THIS PAGE

WAS INTENTIONALLY

LEFT BLANK 
Fig. 10. Block diagram of the apparatus. 


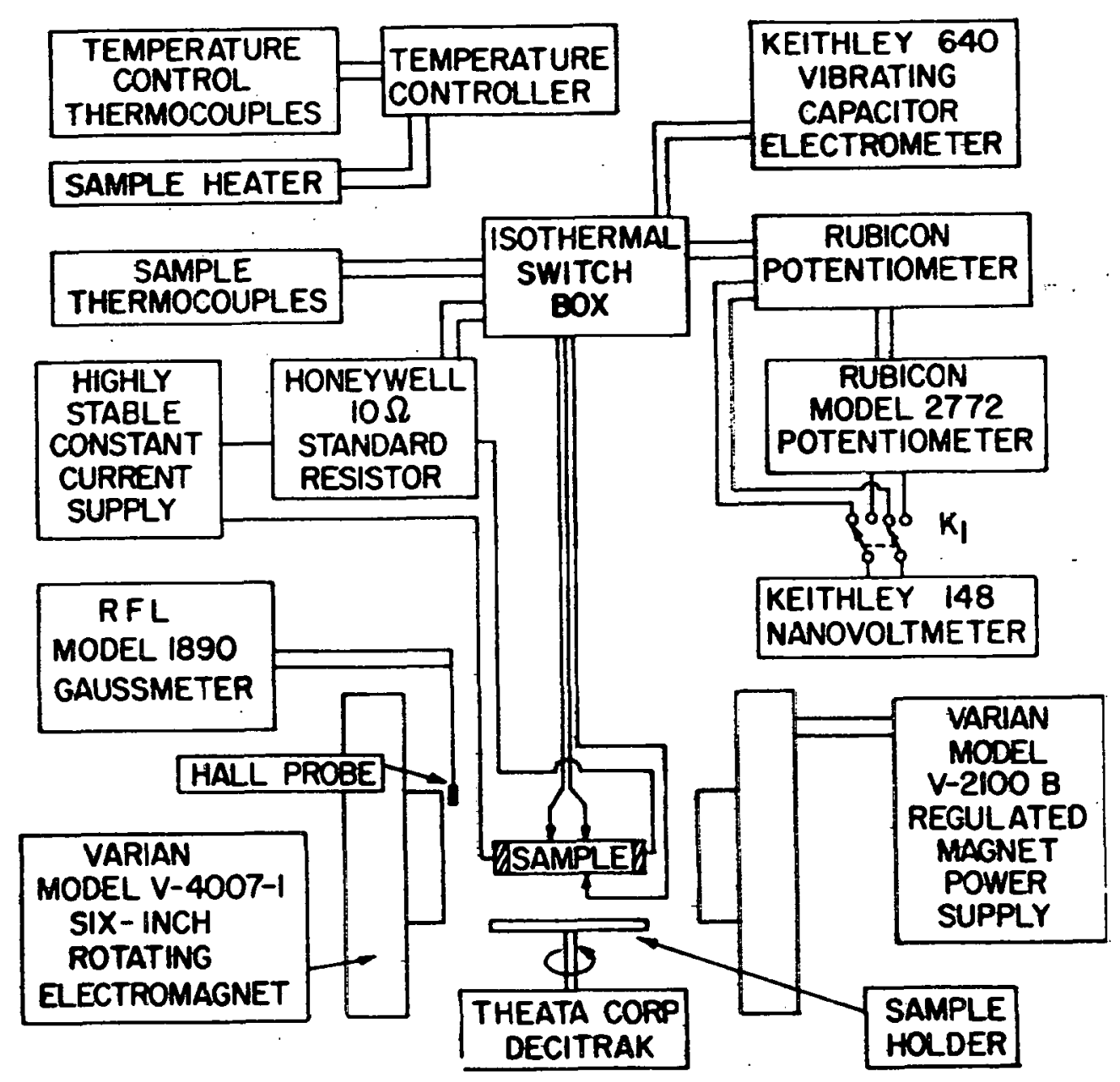


Table 4. Analys is of $\mathrm{Mg}$, 'used in the preparation of $\mathrm{Mg}_{2} \mathrm{Ge}$, for impurities

\begin{tabular}{cc}
\hline Element & $\begin{array}{c}\text { Impurity } \\
\text { (a.t.ppm) }\end{array}$ \\
\hline 0 & 20.0 \\
$\mathrm{Cl}$ & 0.1 \\
$\mathrm{~K}$ & 0.06 \\
$\mathrm{Ca}$ & 0.7 \\
$\mathrm{Cr}$ & 2.0 \\
$\mathrm{Mn}$ & 0.6 \\
$\mathrm{Fe}$ & 1.0 \\
$\mathrm{Ni}$ & 15.0 \\
$\mathrm{Zn}$ & 1.0 \\
\hline
\end{tabular}

analysis was made mass spectrometrically using a Nuclides Analys is Spark Source Mass Spectrography, Nuclide Graph 2.2. 
Table 5. Analysis of $\mathrm{Mg}_{2} \mathrm{Ge}$ samples for impurities.

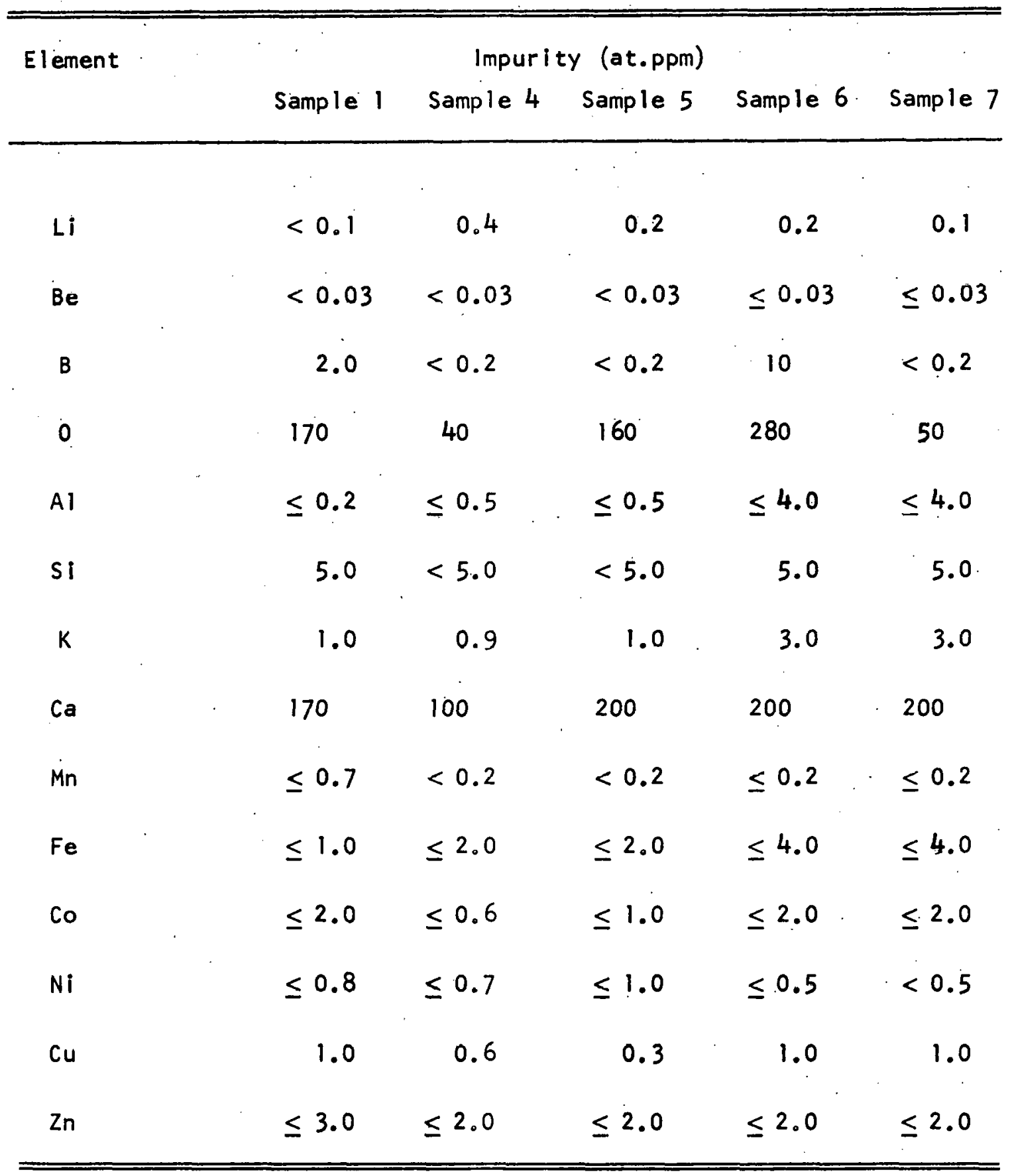

Analysis was made mass spectrometrically using a Nuclides Analysis Spark Source Mass Spectrograph, Nuclide Graph 2.2. 